(2013). Coherence and probability: A probabilistic account of coherence. In M. Araszkiewicz and J. Savelka (Eds.), Coherence: Insights from philosophy, jurisprudence and artificial intelligence (pp. 59-91). Dordrecht: Springer.

DOI: 10.1007/978-94-007-6110-0_3

Visit http://link.springer.com/chapter/10.1007/978-94-007-6110-0 3 for official version

\title{
Coherence and probability: A probabilistic account of coherence
}

\section{William Roche}

Department of Philosophy, Texas Christian University, Fort Worth, TX, USA, e-mail: w.roche@,tcu.edu

\begin{abstract}
I develop a probabilistic account of coherence, and argue that at least in certain respects it is preferable to (at least some of) the main extant probabilistic accounts of coherence: (i) Igor Douven and Wouter Meijs's account, (ii) Branden Fitelson's account, (iii) Erik Olsson's account, and (iv) Tomoji Shogenji's account. Further, I relate the account to an important, but little discussed, problem for standard varieties of coherentism, viz., the "Problem of Justified Inconsistent Beliefs."
\end{abstract}

Keywords Coherence - Coherentism - Probabilistic Accounts of Coherence - Probability • Problem of Justified Inconsistent Beliefs

\section{Introduction}

Is coherence necessary for (epistemic) justification, in that one's beliefs are justified only if one's belief system is coherent? Is coherence sufficient for justification, in that one's beliefs are justified if one's belief system is coherent? ${ }^{1}$ Is coherence truth-conducive, in that coherence implies a high probability of truth, or in that coherence implies a higher probability of truth, or in that, ceteris paribus, greater coherence implies a greater probability of truth? These questions are important, difficult, and have been widely discussed. ${ }^{2}$ It would be helpful in answering such questions, it seems, if we had an account of coherence. It would be especially helpful if we had a quantitative account of coherence. I develop an account of that

${ }^{1}$ There are similar questions about justified (or rational) belief-revision.

2 The third question (i.e., the question of whether coherence is truth-conducive), in particular, has been widely discussed of recent. See Angere (2007, 2008), Bovens and Hartmann (2003a, 2003b, 2005, 2006), Bovens and Olsson (2000, 2002), Cross (1999), Huemer (1997, 2007, 2011), Klein and Warfield (1994, 1996), Meijs and Douven (2007), Merricks (1995), Olsson (2001, 2002, 2005a, 2005b), Olsson and Shogenji (2004), Roche (2010, 2012), Schubert and Olsson (2012), Schupbach (2008), Shogenji (1999, 2005, 2007, forthcoming), van Cleve (2005, 2011), and Wheeler $(2009,2012)$. 
sort (a quantitative account) where coherence is defined (in large part) in terms of probability - a quantitative probabilistic account of coherence. ${ }^{3}$

I do not aim to show that the account developed, hereafter "(CR)," is correct (or adequate), or even that it is preferable to all extant alternative accounts of coherence. I aim, rather, to show that at least in certain respects (CR) is preferable to (at least some of) the main extant probabilistic accounts of coherence: (i) Igor Douven and Wouter Meijs's account (2007), hereafter "(CDM)," (ii) Branden Fitelson's account (2003, 2004), hereafter "(CF),", (iii) Erik Olsson's account (2002, 2005a), hereafter "(CO)," and (iv) Tomoji Shogenji's account $(1999,2001)$, hereafter "(CS)." I leave it for further investigation whether (CR) is preferable all things considered to (CDM), (CF), (CO), and (CS), whether (CR) is preferable all things considered to all alternative probabilistic accounts of coherence (extant or not) in addition to $(\mathrm{CDM}),(\mathrm{CF}),(\mathrm{CO})$, and $(\mathrm{CS}){ }^{7}$ and whether $(\mathrm{CR})$ is preferable all things considered to all nonprobabilistic accounts of coherence. ${ }^{8}$

The paper is organized as follows. In section 2, I set out some desiderata for an adequate account of coherence, and clarify the notion of a "probabilistic" account of coherence. In section 3, I explain, in the following order, (CS), (CO), (CDM), (CF), and (CR). Then, in section 4 , I test the accounts against some cases. I contend that (CR), but not (CS), (CO), (CDM), or (CF), tests well against each case. Next, in section 5, I relate (CR) to an important, but little discussed, problem for standard varieties of coherentism, viz., the "Problem of Justified Inconsistent Beliefs." Last, in section 6, I conclude.

\section{Preliminaries}

\subsection{Some desiderata for an adequate account of coherence}

I take there to be at least three desiderata for an adequate account of coherence. First, an adequate account of coherence should imply that (a) coherence and incoherence come in degrees, (b) logical consistency is insufficient for coherence, (c) the degree to which a set of claims is coherent or incoherent is independent of the ordering of the claims in the set, and (d) no particular size (greater than 1) is needed for a (finite) set of claims to have a degree of

${ }^{3}$ The account is not meant to accurately describe how in fact ordinary people make coherence evaluations. Clarification as to what the account is meant to do is given below in 2.1 .

${ }^{4}$ Douven and Meijs develop three distinct accounts (2007, sec. 3), and argue that one of them is weakly preferable to the other two (2007, sec. 4). The account I call "(CDM)" is the account Douven and Meijs argue to be weakly preferable to the other two accounts.

${ }^{5}$ I have in mind the corrected version. The initial version is given in Fitelson (2003). Two corrections to that version are given in Fitelson (2004).

${ }^{6}$ Olsson holds, at least, that $(\mathrm{CO})$ has some initial appeal.

${ }^{7}$ See, for example, Bovens and Hartmann (2003a, Ch. 2).

${ }^{8}$ See, for instance, Eliasmith and Thagard (1997), Thagard (1989a, 1989b, 1992, 2000, 2004, 2012), Thagard and Nowak (1988), and Thagard and Verbeurgt (1998). And see Siebel $(2005,356-358 ; 2011)$, where it is argued that there can be no adequate probabilistic account of coherence. 
coherence or incoherence. ${ }^{9}$ Suppose $S_{1}=\{p, q, r\}, S_{2}=\{q, r, s\}, S_{3}=\{q, p, r\}$, and $S_{4}=\{p, q$, $r, \sim p\}$, where:

$$
\begin{array}{ll}
p & =\text { No ravens are black; } \\
q & =\text { This bird is a raven; } \\
r & =\text { This bird is black; } \\
s & =\text { Some but very few ravens are black. }{ }^{10}
\end{array}
$$

$S_{1}$ is more incoherent (or has a higher degree of incoherence) than $S_{2}$; this illustrates (a). $S_{2}$ is logically consistent but not coherent ( $q, r$, and $s$ do not "hang together" in the requisite sense); this illustrates (b). $S_{1}$ and $S_{3}$ differ in the ordering of " $p$," " $q$," and " $r$," and yet $S_{1}$ and $S_{3}$ have the same degree of incoherence; this illustrates (c). $S_{2}$ and $S_{4}$ differ in size, and yet each set has a degree of incoherence ( $S_{4}$ 's being greater than $S_{2}$ 's); this illustrates (d).

One terminological note is in order. I use the expression "coherence value" so that any degree of coherence is a coherence value, any degree of incoherence is a coherence value, and the neutral point between incoherence and coherence (if there is such a point) is a coherence value.

Second, an adequate account of coherence should be intuitive or plausible (or at least should not be highly counterintuitive or implausible) in what it implies or does not imply with respect to particular cases (artificial or otherwise). Suppose some account implies that $S_{4}$ is maximally coherent. This implication is not intuitive, in fact, is highly counterintuitive, and so counts (strongly if not decisively) against the account. Or suppose some account is silent on $S_{4}$ in that it has no implication with respect to $S_{4}$ 's coherence value (or even with respect to whether $S_{4}$ has a coherence value). The account thus fails to imply what seems obvious, viz., that $S_{4}$ 's coherence value is very (perhaps maximally) low, that $S_{4}$ 's coherence value is less than $S_{2}$ 's coherence value, and so on. This counts against the account.

Third, an adequate account of coherence should be explanatory. Suppose some account implies that $S_{4}$ is incoherent, but only because the account has a proviso to the effect that $S_{4}$ is incoherent. This counts (though perhaps only weakly) against the account. The account should explain why, and not merely imply that, $S_{4}$ is incoherent. ${ }^{11}$

${ }^{9}$ Here and throughout the paper I assume that only finite sets of two or more claims can have a degree of coherence or incoherence. Cf. Akiba (2000).

${ }^{10}$ This case is adapted from BonJour (1985, 95-96).

${ }^{11}$ Also important, I believe, is the extent to which an account of coherence is fruitful in that it leads to results concerning, say, the reliability of witnesses in a witness scenario, the transmission of confirmation, and so on. For relevant discussion, see Dietrich and Moretti (2005) and Schubert (2012). I do not have the space to evaluate (CDM), (CF), (CO), (CR), and (CS) in terms of fruitfulness. Fitelson $(2003,194)$ gives a desideratum (referred to as "(1)") on which, inter alia, an adequate account of coherence should imply that a set $S=\left\{p_{1}\right.$, . $\left.\ldots, p_{n}\right\}$ is maximally coherent if $p_{1}, \ldots, p_{n}$ are logically equivalent (and $S$ is satisfiable). I would be happy to accept this part of the desideratum; (CR), like (CF), implies that a set $S=$ $\left\{p_{1}, \ldots, p_{n}\right\}$ is maximally coherent if $p_{1}, \ldots, p_{n}$ are logically equivalent (and $S$ is satisfiable). But I would not be happy to accept the desideratum as a whole. See 4.2.1 below. 
(CDM), (CF), (CO), (CR), and (CS) all imply (a)-(d) and so all satisfy the first desideratum. ${ }^{12}$ But not all of those accounts satisfy the second and third desiderata. Or so I argue in section 4 .

\subsection{Probabilistic accounts of coherence}

Let's say that a "probabilistic" account of coherence is an account on which coherence is defined (at least in large part) in terms of probability. ${ }^{13}$ Here is an example. Let $S=\left\{p_{1}, \ldots\right.$, $\left.p_{n}\right\}$. Then, on the "joint probability" account, "(CJ)," the degree to which $S$ is coherent, " $C_{\mathrm{J}}(S)$," is given by:

$$
C_{\mathrm{J}}(S) \quad=\operatorname{Pr}\left(p_{1} \wedge \ldots \wedge p_{n}\right)
$$

(CJ) is implausible. ${ }^{14}$ But, still, (CJ) serves as an example of a probabilistic account of coherence.

Two additional preliminary points are in order. First, on probabilistic accounts of coherence a set of claims can have different coherence values on different probability distributions, indeed, can be coherent on some probability distributions and incoherent on others. ${ }^{15}$ It will help to consider an example. Suppose we have a deck of cards and randomly draw a card from the deck. Let $S=\left\{p_{1}, p_{2}\right\}$, where:

$$
\begin{array}{ll}
p_{1} & =\text { The card selected is a heart; } \\
p_{2} & =\text { The card selected is red. }
\end{array}
$$

Suppose the deck of cards is standard, so that:

${ }^{12}$ It is not trivial that (CDM), (CF), (CO), (CR), and (CS) all imply (a). Not all probabilistic accounts of coherence imply (a). Some probabilistic accounts of coherence are purely qualitative. See Douven and Meijs (2007, sec. 2), where five such accounts are developed and compared. See, also, Lewis $(1946,338)$; there the term "congruence" is used in place of the term "coherence."

${ }^{13}$ By this standard, which admittedly is somewhat vague, each of (CDM), (CF), (CO), $(\mathrm{CR})$, and $(\mathrm{CS})$ is a probabilistic account of coherence. A more stringent standard could be employed. Perhaps then not all of (CDM), (CF), (CO), (CR), and (CS) would be probabilistic accounts of coherence. But, of course, nothing of importance hinges on how the various accounts are categorized.

${ }^{14}$ (CJ) does not do well with some of the cases discussed below in section 4, for example, Tweety and Tweety* (4.3). See Olsson's discussion of " $C_{0}$ ” (2005a, 98-99).

${ }^{15}$ See Douven and Meijs $(2007,407)$. 


\begin{tabular}{ccc}
\hline$p_{1}$ & $p_{2}$ & $\operatorname{Pr}$ \\
\hline $\mathrm{T}$ & $\mathrm{T}$ & .25 \\
$\mathrm{~T}$ & $\mathrm{~F}$ & 0 \\
$\mathrm{~F}$ & $\mathrm{~T}$ & .25 \\
$\mathrm{~F}$ & $\mathrm{~F}$ & .5 \\
\hline
\end{tabular}

On this probability distribution, $C_{\mathrm{J}}(S)=\operatorname{Pr}\left(p_{1} \wedge p_{2}\right)=.25$. Suppose instead the deck of cards is nonstandard in that each of the 26 red cards is a heart, so that:

\begin{tabular}{ccc}
\hline$p_{1}$ & $p_{2}$ & $\operatorname{Pr}$ \\
\hline $\mathrm{T}$ & $\mathrm{T}$ & .5 \\
$\mathrm{~T}$ & $\mathrm{~F}$ & 0 \\
$\mathrm{~F}$ & $\mathrm{~T}$ & 0 \\
$\mathrm{~F}$ & $\mathrm{~F}$ & .5 \\
\hline
\end{tabular}

On this probability distribution, $C_{\mathrm{J}}(S)=\operatorname{Pr}\left(p_{1} \wedge p_{2}\right)=.5$. (CJ) thus implies that $S$ 's coherence value is greater on the second probability distribution than on the first.

Second, a probabilistic account of coherence per se is neutral on the determinants (other than the axioms of the probability calculus) of the probabilistic facts in a given case. Here Shogenji (speaking in terms of beliefs and not in terms of claims) gives a disclaimer to the effect that his project is to give a characterization of coherence but not to identify what relations are responsible for coherence:

This paper does not discuss what makes beliefs (more) coherent; it characterizes coherence of beliefs without attempting to decide what relations-logical, explanatory, etc.- - are responsible for it. Once we separate the characterization of coherence from what is responsible for it, our task is fairly straightforward, but its precise formulation is still helpful in understanding its bearing on truth. (1999, 338, emphasis Shogenji’s)

So one can accept a probabilistic account of coherence, and yet allow that the coherence facts in a given case, though directly determined by the probabilistic facts in the case, are indirectly determined by, say, the explanatory facts in the case - by allowing that at least certain of the probabilistic facts in a given case are determined by (in part) the explanatory facts in the case. $^{16}$

${ }^{16}$ By "explanatory facts" I mean to include facts about the explanatory virtues, for example, simplicity. How can at least certain of the probabilistic facts in a given case be determined by (in part) the explanatory facts in the case? Imagine a case where $h_{1}$ and $h_{2}$ are scientific hypotheses, and $h_{1}$ is preferable to $h_{2}$ in terms of simplicity. One might hold that 


\section{The accounts explained}

In 3.1, I set out (CS). In 3.2, I set out (CO). In 3.3, I set out (CDM), (CF), and (CR).

3.1 (CS)

Let $S=\left\{p_{1}, \ldots, p_{n}\right\}$. Then, on (CS) the degree to which $S$ is coherent, " $C_{\mathrm{S}}(S)$," is given by:

$$
=\frac{\operatorname{Pr}\left(p_{1} \wedge \ldots \wedge p_{n}\right)}{\operatorname{Pr}\left(p_{1}\right) \times \ldots \times \operatorname{Pr}\left(p_{n}\right)}
$$

If $C_{\mathrm{S}}(S)<1, S$ is incoherent. If $C_{\mathrm{S}}(S)=1, S$ is neither coherent nor incoherent. If $C_{\mathrm{S}}(S)>1, S$ is coherent. The minimum value for $C_{\mathrm{S}}(S)$ is 0 . There is no maximum value for $C_{\mathrm{S}}(S)$. If some of the claims in $S$ have a probability of $0, C_{\mathrm{S}}(S)$ is undefined.

Consider a two-member set: $S=\left\{p_{1}, p_{2}\right\}$. By (CS) the degree to which $S$ is coherent is given by:

$C_{\mathrm{S}}(S) \quad=\frac{\operatorname{Pr}\left(p_{1} \wedge p_{2}\right)}{\operatorname{Pr}\left(p_{1}\right) \times \operatorname{Pr}\left(p_{2}\right)}=\frac{\operatorname{Pr}\left(p_{1}\right) \times \operatorname{Pr}\left(p_{2} \mid p_{1}\right)}{\operatorname{Pr}\left(p_{1}\right) \times \operatorname{Pr}\left(p_{2}\right)}=\frac{\operatorname{Pr}\left(p_{2} \mid p_{1}\right)}{\operatorname{Pr}\left(p_{2}\right)}$

If $\operatorname{Pr}\left(p_{2} \mid p_{1}\right)=\operatorname{Pr}\left(p_{2}\right), C_{\mathrm{S}}(S)=1$. If $\operatorname{Pr}\left(p_{2} \mid p_{1}\right)>\operatorname{Pr}\left(p_{2}\right), C_{\mathrm{S}}(S)>1$. If $\operatorname{Pr}\left(p_{2} \mid p_{1}\right)<\operatorname{Pr}\left(p_{2}\right), C_{\mathrm{S}}(S)<$ 1. So, whether $S$ is coherent hinges on whether $p_{1}$ is positively probabilistically relevant to $p_{2}$.

Note that positive (negative) probabilistic relevance is symmetrical. Thus, $p_{1}$ is positively (negatively) probabilistically relevant to $p_{2}$ just in case $p_{2}$ is positively (negatively) probabilistically relevant to $p_{1}$. So (CS) implies that whether a two-member set is coherent hinges on whether the claims in question are positively probabilistically relevant to each other.

(CS) is a generalization of the thesis that whether a two-member set of claims is coherent hinges on whether the claims are positively probabilistically relevant to each other. This thesis has some initial plausibility. Thus so too does (CS). ${ }^{18}$

$\operatorname{Pr}\left(h_{1}\right)>\operatorname{Pr}\left(h_{2}\right)$, and that this is owing in part to the fact that $h_{1}$ is preferable to $h_{2}$ in terms of simplicity. Or suppose (adapting a case from Okasha 2000, 702-703) Smith is in some distress, where $e$ describes Smith's symptoms. Suppose $h_{1}$ is the claim "Smith has pulled a muscle," and $h_{2}$ is the claim "Smith has torn a ligament." Suppose, given background information, $e$ is better explained by $h_{1}$ than by $h_{2}$ in that e would be expected if $h_{l}$ were true but not if $h_{2}$ were true. Then, the idea goes, $\operatorname{Pr}\left(e \mid h_{1}\right)>\operatorname{Pr}\left(e \mid h_{2}\right)$. The issues here, however, are many and difficult, and the relevant literature is vast. See, for starters, Day and Kincaid (1994), Douven (1999, 2011, sec. 4), Harman (1970), Huemer (2009a, 2009b), Iranzo (2008), Lipton (2001, 2004, Ch. 7), Lombrozo (2007), McGrew (2003), Niiniluoto (1999, 2004), Okasha (2000), Psillos (2004, 2007), Salmon (1970, 1990, 2001a, 2001b), Sober (2002), Swinburne (1973, Ch. VII), Tregear (2004), van Fraassen (1989, Ch. 7, sec. 4), and Weisberg (2009).

${ }^{17}$ Shogenji spells out his account of coherence in terms of sets of beliefs, not in terms of sets of claims. But nothing of importance, for my purposes, hinges on this difference.

${ }^{18}$ There are alternative generalizations of the thesis that whether a two-member set of claims is coherent hinges on whether the claims are positively probabilistically relevant to each other. One is developed by Jonah Schupbach (2011). I do not have the space to examine this account (or any of the other alternative generalizations). But what I say in 4.1.1, 4.1.2, and 


\section{$3.2(\mathrm{CO})$}

Let $S=\left\{p_{1}, \ldots, p_{n}\right\}$. Then, on (CO) the degree to which $S$ is coherent, " $C_{\mathrm{O}}(S)$," is given by:

$$
C_{\mathrm{O}}(S) \quad=\frac{\operatorname{Pr}\left(p_{1} \wedge \ldots \wedge p_{n}\right)}{\operatorname{Pr}\left(p_{1} \vee \ldots \vee p_{n}\right)} .
$$

$C_{\mathrm{O}}(S)$ can take values between 0 and 1 (inclusive). If $C_{\mathrm{O}}(S)=0, S$ is maximally incoherent. If $C_{\mathrm{O}}(S)=1, S$ is maximally coherent. It is unspecified where the neutral point is between incoherence and coherence (or even whether there is a neutral point). If $\operatorname{Pr}\left(p_{1} \vee \ldots \vee p_{n}\right)=$ $0, C_{\mathrm{O}}(S)$ is undefined.

Consider a two-member set: $S=\left\{p_{1}, p_{2}\right\}$. By (CO) the degree to which $S$ is coherent is given by:

$$
C_{\mathrm{O}}(S) \quad=\frac{\operatorname{Pr}\left(p_{1} \wedge p_{2}\right)}{\operatorname{Pr}\left(p_{1} \vee p_{2}\right)}
$$

$C_{\mathrm{O}}(S)$ measures how much of the total probability mass assigned to $p_{1}$ and $p_{2}$ falls in their overlap (or intersection). If $p_{1}$ and $p_{2}$ are equivalent to each other so that all of the total probability mass assigned to $p_{1}$ and $p_{2}$ falls in their overlap, then $\operatorname{Pr}\left(p_{1} \wedge p_{2}\right)=\operatorname{Pr}\left(p_{1} \vee p_{2}\right)$ and $C_{\mathrm{O}}(S)=1$. If, to take the other extreme, $p_{1}$ and $p_{2}$ are incompatible with each other so that none of the total probability mass assigned to $p_{1}$ and $p_{2}$ falls in their overlap, then $\operatorname{Pr}\left(p_{1} \wedge p_{2}\right)=$ 0 and $C_{\mathrm{O}}(S)=0$ (assuming $\operatorname{Pr}\left(p_{1} \vee p_{2}\right)>0$ ).

(CO) has some initial plausibility. (CO) is a generalization of the thesis that the degree to which a two-member set of claims is coherent is determined by how much of the total probability mass assigned to the claims falls in their overlap, and this thesis has some initial plausibility. ${ }^{19}$

\section{$3.3(\mathrm{CDM}),(\mathrm{CF})$, and $(\mathrm{CR})$}

(CDM), (CF), and (CR) are all instances of a certain schema (adapted from Douven and Meijs 2007 and Fitelson 2004). So, before setting out the various accounts I want to set out the schema.

Let $S=\left\{p_{1}, \ldots, p_{n}\right\}$. Let $S^{*}=\left\{S^{\prime} \mid S^{\prime}\right.$ is a non-empty subset of $\left.S\right\} .{ }^{20}$ Let $S^{* *}=\left\{\left(S^{\prime}, S^{\prime \prime}\right) \mid\right.$ $S^{\prime}$ and $S^{\prime \prime}$ are non-overlapping members of $\left.S^{*}\right\}$. Let $S^{* * *}=\left\{\left(\Lambda S^{\prime}, \Lambda S^{\prime \prime}\right) \mid\left(S^{\prime}, S^{\prime \prime}\right)\right.$ is a member of $\left.S^{* *}\right\} .^{21}$ Let $m$ be a measure of confirmation (or evidential support). Let $S^{* * * *}=$

4.1.3 about (CS) can also be said mutatis mutandis about the account developed by Schupbach.

${ }^{19}$ Meijs (2006) develops an alternative generalization. And there are yet additional alternative generalizations. I do not, alas, have the space to examine them. What I say in 4.1.2 about (CO), though, can also be said mutatis mutandis about the account developed by Meijs.

${ }^{20}$ It might be better to define $S$ so that it is an ordered set, and to define $S^{*}$ so that $S^{\prime}$ is a nonempty subsequence of $S$. See Schubert (2012, 311-312).

${ }^{21}$ If $S^{\prime}$ has just one member, then $\Lambda S^{\prime}$ is simply that member. Likewise with respect to $S^{\prime}$. 
$\left\{m\left(\wedge S^{\prime}, \wedge S^{\prime \prime}\right) \mid\left(\wedge S^{\prime}, \wedge S^{\prime \prime}\right)\right.$ is a member of $\left.S^{* * *}\right\}$. Then, by account "(CX)" the degree to which $S$ is coherent, " $C_{\mathrm{X}}(S)$," is given by:

$$
C_{\mathrm{X}}(S) \quad=\operatorname{mean}\left(S^{* * * *}\right) .
$$

Different measures of confirmation can thus be used to generate different probabilistic accounts of coherence. ${ }^{22}$

It will help to consider a few examples. First, suppose $S=\left\{p_{1}, p_{2}\right\}$. Then:

$$
\begin{array}{lll}
S^{*} & = & \left\{\left\{p_{1}\right\},\left\{p_{2}\right\},\left\{p_{1}, p_{2}\right\}\right\} ; \\
S^{* *} & = & \left\{\left(\left\{p_{1}\right\},\left\{p_{2}\right\}\right),\left(\left\{p_{2}\right\},\left\{p_{1}\right\}\right)\right\} ; \\
S^{* * *} & =\left\{\left(p_{1}, p_{2}\right),\left(p_{2}, p_{1}\right)\right\} ; \\
S^{* * * *} & =\left\{m\left(p_{1}, p_{2}\right), m\left(p_{2}, p_{1}\right)\right\} ; \\
C_{\mathrm{X}}(S) & =\operatorname{mean}\left(S^{* * * *}\right)=\frac{m\left(p_{1}, p_{2}\right)+m\left(p_{2}, p_{1}\right)}{2} .
\end{array}
$$

Next, suppose $S=\left\{p_{1}, p_{2}, p_{3}\right\}$. Then:

$$
\begin{aligned}
& S^{*} \quad=\left\{\left\{p_{1}\right\},\left\{p_{2}\right\},\left\{p_{3}\right\},\left\{p_{1}, p_{2}\right\},\left\{p_{1}, p_{3}\right\},\left\{p_{2}, p_{3}\right\},\left\{p_{1}, p_{2}, p_{3}\right\}\right\} ; \\
& S^{* *}=\left\{\left(\left\{p_{1}\right\},\left\{p_{2}\right\}\right),\left(\left\{p_{1}\right\},\left\{p_{3}\right\}\right),\left(\left\{p_{2}\right\},\left\{p_{1}\right\}\right),\left(\left\{p_{2}\right\},\left\{p_{3}\right\}\right),\left(\left\{p_{3}\right\},\left\{p_{1}\right\}\right),\right. \\
& S^{* * *}=\left\{\left(p_{1}, p_{2}\right),\left(p_{1}, p_{3}\right),\left(p_{2}, p_{1}\right),\left(p_{2}, p_{3}\right),\left(p_{3}, p_{1}\right),\left(p_{3}, p_{2}\right),\left(p_{1}, p_{2} \wedge p_{3}\right),\left(p_{2}, p_{1} \wedge\right.\right. \\
& \left.\left.p_{3}\right),\left(p_{3}, p_{1} \wedge p_{2}\right),\left(p_{1} \wedge p_{2}, p_{3}\right),\left(p_{1} \wedge p_{3}, p_{2}\right),\left(p_{2} \wedge p_{3}, p_{1}\right)\right\} \text {; } \\
& S^{* * * *}=\left\{m\left(p_{1}, p_{2}\right), m\left(p_{1}, p_{3}\right), m\left(p_{2}, p_{1}\right), m\left(p_{2}, p_{3}\right), m\left(p_{3}, p_{1}\right), m\left(p_{3}, p_{2}\right), m\left(p_{1}, p_{2} \wedge\right.\right. \\
& \left.p_{3}\right), m\left(p_{2}, p_{1} \wedge p_{3}\right), m\left(p_{3}, p_{1} \wedge p_{2}\right), m\left(p_{1} \wedge p_{2}, p_{3}\right), m\left(p_{1} \wedge p_{3}, p_{2}\right), m\left(p_{2} \wedge\right. \\
& \left.\left.p_{3}, p_{1}\right)\right\} \text {; } \\
& m\left(p_{1}, p_{2}\right)+m\left(p_{1}, p_{3}\right)+m\left(p_{2}, p_{1}\right) \\
& +m\left(p_{2}, p_{3}\right)+m\left(p_{3}, p_{1}\right)+m\left(p_{3}, p_{2}\right) \\
& +m\left(p_{1}, p_{2} \wedge p_{3}\right)+m\left(p_{2}, p_{1} \wedge p_{3}\right)+m\left(p_{3}, p_{1} \wedge p_{2}\right) \\
& C_{\mathrm{X}}(S)=\operatorname{mean}(\mathrm{S} * * * *)=\frac{+m\left(p_{1} \wedge p_{2}, p_{3}\right)+m\left(p_{1} \wedge p_{3}, p_{2}\right)+m\left(p_{2} \wedge p_{3}, p_{1}\right)}{12} \text {. }
\end{aligned}
$$

So, when $n=2, C_{\mathrm{X}}(S)$ is the mean of 2 confirmation values, and when $n=3, C_{\mathrm{X}}(S)$ is the mean of 12 confirmation values.

It can be shown that, where $S=\left\{p_{1}, \ldots, p_{n}\right\}, C_{\mathrm{X}}(S)$ is the mean of $\sum_{i=1}^{n-1}\left(\begin{array}{l}n \\ i\end{array}\right)\left(2^{n-i}-1\right)$ confirmation values, ${ }^{23}$ or, equivalently, of $3^{n}-2^{n+1}+1$ confirmation values. ${ }^{24}$ So, when $n=4$,

${ }^{22}$ See Eells and Fitelson (2002) for an overview of the main extant measures of confirmation, and for defense of the claim that certain symmetry considerations favor the "difference" measure and (a logarithm-based version of) the "likelihood" measure over their rivals. See also Crupi et al. (2007). 
$C_{\mathrm{X}}(S)$ is the mean of 50 confirmation values, when $n=5, C_{\mathrm{X}}(S)$ is the mean of 180 confirmation values, when $n=6, C_{\mathrm{X}}(S)$ is the mean of 602 confirmation values, and so on.

Instances of the schema thus all agree in the idea that the degree to which a set of claims is coherent is equal to the average degree to which the (claims, or iterated conjunctions thereof, in the) various non-empty and non-overlapping subsets of the set confirm each other. ${ }^{25}$ The best possible case is where the various subsets all maximally confirm each other. The worst possible case is where the various subsets all maximally disconfirm each other.

Let's turn now to (CDM), (CF), and (CR). I begin with (CDM).

$(\mathrm{CDM})$ involves the difference measure of confirmation:

$d(h, e) \quad=\quad \operatorname{Pr}(h \mid e)-\operatorname{Pr}(h)^{26}$

Suppose $S=\left\{p_{1}, p_{2}\right\}$. Then, by (CDM) the degree to which $S$ is coherent, " $C_{\mathrm{DM}}(S)$," is given by:

$C_{\mathrm{DM}}(S)=\operatorname{mean}\left(\left\{d\left(p_{1}, p_{2}\right), d\left(p_{2}, p_{1}\right)\right\}\right)$

$$
=\frac{\left[\operatorname{Pr}\left(p_{1} \mid p_{2}\right)-\operatorname{Pr}\left(p_{1}\right)\right]+\left[\operatorname{Pr}\left(p_{2} \mid p_{1}\right)-\operatorname{Pr}\left(p_{2}\right)\right]}{2} .
$$

$C_{\mathrm{DM}}(S)$ can take values between -1 and 1 (not inclusive). ${ }^{27}$ (CDM) is naturally understood so that if $C_{\mathrm{DM}}(S)<0, S$ is incoherent, if $C_{\mathrm{DM}}(S)=0, S$ is neither coherent nor incoherent, and if $C_{\mathrm{DM}}(S)>0, S$ is coherent (though strictly speaking Douven and Meijs never explicitly say this; see Siebel 2005, 348-349). If some of the claims in $S$ have a probability of $0, C_{\mathrm{DM}}(S)$ is undefined.

Note that one can find (CDM) to be attractive even if one does not find the difference measure to be attractive qua measure of confirmation. Likewise with respect to the various

23 That $C_{\mathrm{X}}(S)$ is the mean of $\sum_{i=1}^{n-1}\left(\begin{array}{l}n \\ i\end{array}\right)\left(2^{n-i}-1\right)$ confirmation values follows, ultimately, from the fact that $S^{* *}$ has exactly $\sum_{i=1}^{n-1}\left(\begin{array}{l}n \\ i\end{array}\right)\left(2^{n-i}-1\right)$ members. See Douven and Meijs $(2007,412$, n. 15).

${ }^{24}$ The result that $C_{\mathrm{X}}(S)$ is the mean of $3^{n}-2^{n+1}+1$ confirmation values is due essentially to Kyle Kloster (to whom I am grateful).

${ }^{25}$ Douven and Meijs (2007, secs. 2-3) give a compelling defense of this idea. This defense, though, can be strengthened a bit. Douven and Meijs fail to prove "Conjecture 2.1" (2007, 408). The thesis in question-viz., that "one-any + partition coherence" does not entail "any-any coherence"-is true, as Douven and Meijs conjecture, and can be proven.

${ }^{26}$ Here " $h$ " and " $e$ " can be iterated conjunctions, e.g., $p_{1} \wedge p_{2} \wedge p_{3} . d(h, e)$ is defined only if $e$ has a positive probability.

${ }^{27}$ Why cannot $C_{\mathrm{DM}}(S)=1$ ? $C_{\mathrm{DM}}(S)=1$ only if each of the various confirmation values equals 1 . But, none of the various confirmation values equals 1 . This is because $d(h, e)$ cannot equal 1. Suppose $\operatorname{Pr}(h)=0$. Then, assuming $\operatorname{Pr}(h \mid e)$ is defined, $\operatorname{Pr}(h \mid e)=0$, hence $\operatorname{Pr}(h \mid e)-$ $\operatorname{Pr}(h)=0$. Suppose, instead, $\operatorname{Pr}(h)>0$. Then, even if $\operatorname{Pr}(h \mid e)=1$, it follows that $\operatorname{Pr}(h \mid e)-$ $\operatorname{Pr}(h)<1$. Why cannot $C_{\mathrm{DM}}(S)=-1$ ? $C_{\mathrm{DM}}(S)=-1$ only if each of the various confirmation values equals -1 . But, none of the various confirmation values equals -1 . This is because $d(h$, e) cannot equal -1 . Suppose $\operatorname{Pr}(h)=1$. Then, assuming $\operatorname{Pr}(h \mid e)$ is defined, $\operatorname{Pr}(h \mid e)=1$, hence $\operatorname{Pr}(h \mid e)-\operatorname{Pr}(h)=0$. Suppose, instead, $\operatorname{Pr}(h)<1$. Then, even if $\operatorname{Pr}(h \mid e)=0$, it follows that $\operatorname{Pr}(h \mid e)-\operatorname{Pr}(h)>-1$. 
alternative instances of the schema above and the measures of confirmation involved in them. ${ }^{28}$ The crucial question is whether the accounts are intuitive or plausible in what they imply or do not imply with respect to particular cases, and whether the accounts satisfy the various other desiderata for an adequate account of coherence.

$(\mathrm{CF})$ is just like (CDM) except that $(\mathrm{CF})$ involves the following measure of confirmation:

$$
\begin{aligned}
f(h, e) & =1 & & \text { if } e \vDash h \text { and } e \not \perp ; \\
& =-1 & & \text { if } e \vDash \sim h ; \\
& =\frac{\operatorname{Pr}(e \mid h)-\operatorname{Pr}(e \mid \sim h)}{\operatorname{Pr}(e \mid h)+\operatorname{Pr}(e \mid \sim h)} & & \text { if } e \not h \text { and } e \not \approx \sim{ }^{29}
\end{aligned}
$$

Suppose $S=\left\{p_{1}, p_{2}\right\}$, and $p_{1} \not p_{2}, p_{1} \not \neq \sim p_{2}, p_{2} \not \neq p_{1}$, and $p_{2} \not \neq \sim p_{1}$. Then, by (CF) the degree to which $S$ is coherent, " $C_{\mathrm{F}}(S)$," is given by:

$C_{\mathrm{F}}(S) \quad=\operatorname{mean}\left(\left\{f\left(p_{1}, p_{2}\right), f\left(p_{2}, p_{1}\right)\right\}\right)$

$$
=\frac{\frac{\operatorname{Pr}\left(p_{2} \mid p_{1}\right)-\operatorname{Pr}\left(p_{2} \mid \sim p_{1}\right)}{\operatorname{Pr}\left(p_{2} \mid p_{1}\right)+\operatorname{Pr}\left(p_{2} \mid \sim p_{1}\right)}+\frac{\operatorname{Pr}\left(p_{1} \mid p_{2}\right)-\operatorname{Pr}\left(p_{1} \mid \sim p_{2}\right)}{\operatorname{Pr}\left(p_{1} \mid p_{2}\right)+\operatorname{Pr}\left(p_{1} \mid \sim p_{2}\right)}}{2} .
$$

$C_{\mathrm{F}}(S)$ can take values between -1 and 1 (inclusive). If $C_{\mathrm{F}}(S)<0, S$ is incoherent. If $C_{\mathrm{F}}(S)=0, S$ is neither coherent nor incoherent. If $C_{\mathrm{F}}(S)>0, S$ is coherent.

$(\mathrm{CR})$ is just like (CDM) and (CF) except that the measure of confirmation involved in $(\mathrm{CR})$ is the following:

$$
\begin{aligned}
a(h, e) & =1 & & \text { if } e \vDash h \text { and } e \not \neq \perp ; \\
& =0 & & \text { if } e \vDash \sim h ; \\
& =\operatorname{Pr}(h \mid e) & & \text { if } e \not h \text { and } e \not \neq \sim h .^{30}
\end{aligned}
$$

Let $S=\left\{p_{1}, p_{2}\right\}$, and suppose $p_{1} \not \neq p_{2}, p_{1} \not \neq \sim p_{2}, p_{2} \not \neq p_{1}$, and $p_{2} \not \neq \sim p_{1}$. Then, by (CR) the degree to which $S$ is coherent, " $C_{\mathrm{R}}(S)$," is given by:

$$
=\operatorname{mean}\left(\left\{a\left(p_{1}, p_{2}\right), a\left(p_{2}, p_{1}\right)\right\}\right)=\frac{\operatorname{Pr}\left(p_{1} \mid p_{2}\right)+\operatorname{Pr}\left(p_{2} \mid p_{1}\right)}{2}
$$

$C_{\mathrm{R}}(S)$ can take values between 0 and 1 (inclusive). (CR) is naturally understood so that the neutral point between incoherence and coherence is .5 .

\footnotetext{
${ }^{28}$ Douven and Meijs $(2007,411$, n. 14) make a point to this effect.

${ }^{29}$ This measure of confirmation is a variant of John Kemeny and Paul Oppenheim's measure (1952).

30 This measure is best seen as a measure of absolute, as opposed to incremental, confirmation. Thus the " $a$ " in " $a(h, e)$."
} 


\section{The accounts tested}

In 4.1, I discuss some problem cases for (CS), (CO), and (CDM) (but note that the case discussed in 4.1.1 is a problem case just for (CS) and (CDM)). In 4.2, I discuss some problem cases for $(\mathrm{CF})$. In 4.3, I discuss some additional test cases.

4.1 Some problem cases for (CS), (CO), and (CDM)

\subsubsection{Sets of contradictory claims}

Suppose a fair six-sided die was just rolled. Let $S_{5}=\{t, \sim t\}$, where:

$t \quad=\quad$ The die came up two.

$S_{5}$, it seems, is incoherent, indeed, is highly if not maximally incoherent. Likewise, it seems, with respect to any set of contradictory claims.

(CS) and (CDM), though, cannot explain this (why any set of contradictory claims is highly if not maximally incoherent). There are sets of contradictory claims on which (CS) and $(\mathrm{CDM})$ remain silent. Let $S_{6}=\{f, \sim f\}$, where:

$$
\text { f } \quad=2+2=4 \text {. }
$$

$S_{6}$, like $S_{5}$, is highly if not maximally incoherent. But consider:

$$
\begin{aligned}
C_{\mathrm{S}}\left(S_{6}\right) \quad= & \frac{\operatorname{Pr}(f \wedge \sim f)}{\operatorname{Pr}(f) \times \operatorname{Pr}(\sim f)} ; \\
C_{\mathrm{DM}}\left(S_{6}\right)= & \operatorname{mean}(\{d(f, \sim f), d(\sim f, f)\}) \\
& =\frac{[\operatorname{Pr}(f \mid \sim f)-\operatorname{Pr}(f)]+[\operatorname{Pr}(\sim f \mid f)-\operatorname{Pr}(\sim f)]}{2} .
\end{aligned}
$$

Given that $\operatorname{Pr}(\sim f)=0,{ }^{31}$ it follows that $\operatorname{Pr}(f) \times \operatorname{Pr}(\sim f)=0$, hence $C_{\mathrm{S}}\left(S_{6}\right)$ is undefined, ${ }^{32}$ and it follows that $\operatorname{Pr}(f \mid \sim f)$ is undefined, thus $d(f, \sim f)$ is undefined, thus $C_{\mathrm{DM}}\left(S_{6}\right)$ is undefined. ${ }^{33}$

${ }^{31} \mathrm{I}$ am assuming, here and throughout the paper, that if a claim $p$ is necessarily true, then, on any (admissible) probability function, $\operatorname{Pr}(p)=1$, and that if a claim $p$ is necessarily false, then, on any (admissible) probability function, $\operatorname{Pr}(p)=0$. In assuming this I am glossing over some difficult issues in epistemology, philosophy of language, and philosophy of mind. I leave it for further investigation how best to treat these issues and whether the best treatment would require substantive changes to the main points of this paper. For relevant discussion, see Chalmers (2011), Douven and Meijs (2007, sec. 5.1), Garber (1983), and Swinburne (1973, Ch. IV).

${ }^{32}$ This point can be established in two other ways. First, observe that:

$$
=\frac{\operatorname{Pr}(f \wedge \sim f)}{\operatorname{Pr}(f) \times \operatorname{Pr}(\sim f)}=\frac{\operatorname{Pr}(\sim f) \times \operatorname{Pr}(f \mid \sim f)}{\operatorname{Pr}(f) \times \operatorname{Pr}(\sim f)}=\frac{\operatorname{Pr}(f \mid \sim f)}{\operatorname{Pr}(f)} .
$$

Since the numerator in $\frac{\operatorname{Pr}(f \mid \sim f)}{\operatorname{Pr}(f)}$ is undefined, $C_{\mathrm{S}}\left(S_{6}\right)$ is undefined. Second, observe that: 
$(\mathrm{CO}),(\mathrm{CF})$, and (CR), by contrast, imply that $S_{6}$ is maximally incoherent:

$$
\begin{array}{ll}
C_{\mathrm{O}}\left(S_{6}\right) & =\frac{\operatorname{Pr}(f \wedge \sim f)}{\operatorname{Pr}(f \vee \sim f)}=\frac{0}{1}=0 ; \\
C_{\mathrm{F}}\left(S_{6}\right) & =\operatorname{mean}(\{f(f, \sim f), f(\sim f, f)\})=\frac{-1+-1}{2}=-1 ; \\
C_{\mathrm{R}}\left(S_{6}\right) & =\operatorname{mean}(\{a(f, \sim f), a(\sim f, f)\})=\frac{0+0}{2}=0 .
\end{array}
$$

$f(f, \sim f)=-1$ and $a(f, \sim f)=0$, since $\sim f \vDash \sim f . f(\sim f, f)=-1$ and $a(\sim f, f)=0$, given that $f \vDash \sim \sim f$.

It is clear, of course, without any appeal to coherence considerations that one should not believe the claims in $S_{6}$. The point remains, however, that $S_{6}$ is incoherent and neither (CS) nor $(\mathrm{CDM})$ can explain this.

(CS) could be modified to say that if the members of a set $S=\left\{p_{1}, p_{2}\right\}$ are contradictory claims, then $S$ is maximally incoherent even if $\operatorname{Pr}\left(p_{1}\right) \times \operatorname{Pr}\left(p_{2}\right)=0$. Likewise, $(\mathrm{CDM})$ could be modified to say that if the members of a set $S=\left\{p_{1}, p_{2}\right\}$ are contradictory claims, then $S$ is maximally incoherent even if $d\left(p_{1}, p_{2}\right)$ or $d\left(p_{2}, p_{1}\right)$ is undefined. But then (CS) and (CDM) would be unable to explain why sets of contradictory claims one member of which is a necessary falsehood are incoherent.

\subsubsection{Sets of necessary falsehoods}

Let $S_{7}=\{f, s\}$, where:

$$
\begin{array}{ll}
f & =2+2=5 ; \\
s & =2+2=6 .
\end{array}
$$

$S_{7}$, it seems, is incoherent, indeed, is highly if not maximally incoherent; $f \vDash \sim s$, and $s \vDash \sim f$. Likewise with respect to any set of necessary falsehoods.

(CS), (CO), and (CDM), however, are silent on $S_{7}$. Consider:

$$
C_{\mathrm{S}}\left(S_{6}\right) \quad=\frac{\operatorname{Pr}(f \wedge \sim f)}{\operatorname{Pr}(f) \times \operatorname{Pr}(\sim f)}=\frac{\operatorname{Pr}(f) \times \operatorname{Pr}(\sim f \mid f)}{\operatorname{Pr}(f) \times \operatorname{Pr}(\sim f)}=\frac{\operatorname{Pr}(\sim f \mid f)}{\operatorname{Pr}(\sim f)} .
$$

Since the denominator in $\frac{\operatorname{Pr}(\sim f \mid f)}{\operatorname{Pr}(\sim f)}$ equals $0, C_{\mathrm{S}}\left(S_{6}\right)$ is undefined.

${ }^{33}$ Douven and Meijs (2007, sec. 5.1) raise a problem for (CDM), and for certain other accounts of coherence, and give two proposals for solving the problem. Each proposal has the result that the only sets that should be considered when evaluating (CDM) are sets consisting of pairwise logically independent claims. This result entails that, since $S_{6}$ is not a set consisting of pairwise logically independent claims, $S_{6}$ should not be considered when evaluating (CDM). It seems clear, though, that $S_{6}$ has a coherence value, in fact a very low if not maximally low coherence value. Moreover, it seems clear that many sets consisting of pairwise logically dependent claims have coherence values. So for the purposes of this paper I shall assume that the two proposals given by Douven and Meijs should be rejected and that the problem raised by Douven and Meijs for (CDM), and for the other accounts in question, can be adequately answered without appeal to those proposals. See Huemer $(2011,46-47)$ and Schubert (2012, 311-312). 


$$
\begin{array}{ll}
C_{\mathrm{S}}\left(S_{7}\right) & =\frac{\operatorname{Pr}(f \wedge s)}{\operatorname{Pr}(f) \times \operatorname{Pr}(s)} ; \\
C_{\mathrm{O}}\left(S_{7}\right) & =\frac{\operatorname{Pr}(f \wedge s)}{\operatorname{Pr}(f \vee s)} ; \\
C_{\mathrm{DM}}\left(S_{7}\right) & =\operatorname{mean}(\{d(f, s), d(s, f)\})=\frac{[\operatorname{Pr}(f \mid s)-\operatorname{Pr}(f)]+[\operatorname{Pr}(s \mid f)-\operatorname{Pr}(s)]}{2} .
\end{array}
$$

Clearly, $C_{\mathrm{S}}\left(S_{7}\right)$ and $C_{\mathrm{O}}\left(S_{7}\right)$ are undefined. $C_{\mathrm{DM}}\left(S_{7}\right)$ is undefined because, since both $\operatorname{Pr}(f \mid s)$ and $\operatorname{Pr}(s \mid f)$ are undefined, both $d(f, s)$ and $d(s, f)$ are undefined. The same is true of any alternative set of necessary falsehoods: (CS), (CO), and (CDM) remain silent.

$(\mathrm{CF})$ and (CR), by contrast, do well with $S_{7}$ :

$$
\begin{array}{ll}
C_{\mathrm{F}}\left(S_{7}\right) & =\operatorname{mean}(\{f(f, s), f(s, f)\})=\frac{-1+-1}{2}=-1 ; \\
C_{\mathrm{R}}\left(S_{7}\right) & =\operatorname{mean}(\{a(f, s), a(s, f)\})=\frac{0+0}{2}=0 .
\end{array}
$$

$f(f, s)=-1$ and $a(f, s)=0$, since $s \vDash \sim f . f(s, f)=-1$ and $a(s, f)=0$, given that $f \vDash \sim s$. Likewise for any alternative set of necessary falsehoods: (CF) and (CR) imply maximal incoherence.

(CS), (CO), and (CDM) could be modified to say, respectively, that any set $S=\left\{p_{1}, p_{2}\right\}$ consisting of necessary falsehoods is maximally incoherent even if $\operatorname{Pr}\left(p_{1}\right) \times \operatorname{Pr}\left(p_{2}\right)=0$, that any set $S=\left\{p_{1}, p_{2}\right\}$ consisting of necessary falsehoods is maximally incoherent even if $\operatorname{Pr}\left(p_{I} \vee\right.$ $\left.p_{2}\right)=0,{ }^{34}$ and that any set $S=\left\{p_{1}, p_{2}\right\}$ consisting of necessary falsehoods is maximally incoherent even if $d\left(p_{1}, p_{2}\right)$ and $d\left(p_{2}, p_{1}\right)$ are undefined. But then (CS), (CO), and (CDM) would be unable to explain why sets of that sort are maximally incoherent.

\subsubsection{Sets involving a necessary falsehood}

Suppose $S_{8}=\left\{p_{1} \ldots, p_{n}\right\}$, where $\left\{p_{1} \ldots, p_{n}\right\}$ is very large and highly coherent (on any account of coherence). Suppose (adapting a case from Foley 1979, 249) $S_{9}=\left\{p_{1}, \ldots, p_{n}\right.$, $\left.p_{n+1}\right\}$, where $p_{n+1}$ is the necessary falsehood that $3^{8}$ is greater than $6562 .{ }^{35} S_{9}$, it seems, has a lesser coherence value than $S_{8}$, but, still, not the minimum coherence value. $S_{9}$ has a greater coherence value than, say, the set $\{p, \sim p\}$, where $p$ is the claim that all ravens are black. $S_{8}$ is highly coherent and, so, certain of the claims in $S_{9}$-viz., $p_{1}, \ldots, p_{n}$-hang together in the requisite sense. By contrast, none of the claims in the set $\{p, \sim p\}$ hang together in the requisite sense.

$S_{9}$ is problematic for $(\mathrm{CO})$. Consider:

$$
C_{\mathrm{O}}\left(S_{9}\right) \quad=\frac{\operatorname{Pr}\left(p_{1} \wedge \ldots \wedge p_{n} \wedge p_{n+1}\right)}{\operatorname{Pr}\left(p_{1} \vee \ldots \vee p_{n} \vee p_{n+1}\right)}
$$

\footnotetext{
${ }^{34}$ A slight variant of this proposal with respect to (CO) is given in Glass $(2005,384, \mathrm{n} .7)$ $353^{8}=6561$.
} 
Suppose $\operatorname{Pr}\left(p_{1} \vee \ldots \vee p_{n} \vee p_{n+1}\right)>0$. Then, since $\operatorname{Pr}\left(p_{1} \wedge \ldots \wedge p_{n} \wedge p_{n+1}\right)=0$, it follows that $C_{\mathrm{O}}\left(S_{9}\right)=0$. (CO) thus implies that, even though $S_{8}$ is highly coherent and $S_{9}$ differs from $S_{8}$ only in that $p_{n+1}$ (a necessary falsehood) is a member of $S_{9}, S_{9}$ is maximally incoherent.

$S_{9}$ is also problematic for (CS) and (CDM). Consider:

$$
\begin{aligned}
C_{\mathrm{S}}\left(S_{9}\right) & =\frac{\operatorname{Pr}\left(p_{1} \wedge \ldots \wedge p_{n} \wedge p_{n+1}\right)}{\operatorname{Pr}\left(p_{1}\right) \times \ldots \times \operatorname{Pr}\left(p_{n}\right) \times \operatorname{Pr}\left(p_{n+1}\right)} \\
C_{\mathrm{DM}}\left(S_{9}\right) & =\operatorname{mean}\left(\left\{d\left(p_{1}, p_{2}\right), \ldots d\left(p_{1}, p_{\mathrm{n}+1}\right), \ldots\right\}\right) .
\end{aligned}
$$

Since $\operatorname{Pr}\left(p_{n+1}\right)=0$, it follows that $\operatorname{Pr}\left(p_{1}\right) \times \ldots \times \operatorname{Pr}\left(p_{n}\right) \times \operatorname{Pr}\left(p_{n+1}\right)=0$, hence $C_{\mathrm{S}}\left(S_{9}\right)$ is undefined. It also follows that $\operatorname{Pr}\left(p_{1} \mid p_{n+1}\right)$ is undefined, thus $d\left(p_{1}, p_{n+1}\right)$ is undefined, thus $C_{\mathrm{DM}}\left(S_{9}\right)$ is undefined. So, $(\mathrm{CS})$ and $(\mathrm{CDM})$ are silent on $S_{9}{ }^{36}$

(CF) and (CR), on the other hand, do well with $S_{9}$. Suppose $p_{2} \vDash p_{1}$ and $p_{2} \not \vDash \perp$. Then it follows that:

$$
\begin{array}{ll}
C_{\mathrm{F}}\left(S_{9}\right) & =\operatorname{mean}\left(\left\{f\left(p_{1}, p_{2}\right), \ldots\right\}\right)=\operatorname{mean}(\{1, \ldots\})>-1 \\
C_{\mathrm{R}}\left(S_{9}\right) & =\operatorname{mean}\left(\left\{a\left(p_{1}, p_{2}\right), \ldots\right\}\right)=\operatorname{mean}(\{1, \ldots\})>0 .
\end{array}
$$

Note that $C_{\mathrm{F}}(S)=-1$ only when each of the various confirmation values (over which the mean is taken) equals -1 , and that $C_{\mathrm{R}}(S)=0$ only when each of the various confirmation values (over which the mean is taken) equals $0 .^{37}$

(CS) could be modified to say that if a claim in a set $S=\left\{p_{1}, p_{2}, \ldots, p_{n}\right\}$ has a probability of 0 , then, though $\operatorname{Pr}\left(p_{1}\right) \times \operatorname{Pr}\left(p_{2}\right) \times \ldots \times \operatorname{Pr}\left(p_{n}\right)=0, S$ is maximally incoherent. (CDM) could be modified in a similar fashion. But then, for one thing, though (CS) and (CDM) would not be silent on $S_{9}$, (CS) and (CDM) would yield the wrong result with respect to $S_{9}$.

\subsection{Some problem cases for (CF)}

(CF), like (CR), does well with sets of contradictory claims, sets of necessary falsehoods, and sets involving a necessary falsehood (at least in that (CF), like (CR), implies that sets involving a necessary falsehood can have a coherence value greater than the minimum). I turn now to some test cases with which, arguably, (CF), unlike (CR), does not do well.

\footnotetext{
${ }^{36}$ There are variants of the case where $(\mathrm{CDM})$ is silent on the larger set but (CS) is not. Suppose $S_{9^{*}}$ is just like $S_{8}$ except that $S_{9 *}$ includes $t w o$ additional claims, $p_{n+1}$ and $p_{n+2}$, where each claim has a nonextreme probability and the one claim entails the falsity of the other claim. (CDM) is silent on $S_{9 *} ; \operatorname{Pr}\left(p_{n+1} \wedge p_{n+2}\right)=0$, thus $\operatorname{Pr}\left(p_{1} \mid p_{n+1} \wedge p_{n+2}\right)$ is undefined, thus $d\left(p_{1}, p_{n+1} \wedge p_{n+2}\right)$ is undefined, thus $C_{\mathrm{DM}}\left(S_{9^{*}}\right)$ is undefined. (CS), by contrast, is not silent on $S_{9^{*}} . C_{\mathrm{S}}\left(S_{9^{*}}\right)=0$ and so (CS) implies that $S_{9^{*}}$ is maximally incoherent. This, it seems, is the wrong result. $S_{9 *}$ has a lesser coherence value than $S_{8}$. But, since (by hypothesis) certain of the claims in $S_{9^{*}}$ (namely, $p_{1}, \ldots, p_{n}$ ) hang together in the requisite sense, $S_{9^{*}}$ is not maximally incoherent.

${ }^{37}$ In section 5 , below, I consider the question of whether $C_{\mathrm{R}}\left(S_{9}\right)$ can have a coherence value greater than .5 .
} 


\subsubsection{Pickpocket, Rabbit, and Rabbit*}

Mark Siebel argues that (CF) is inadequate in its implications with respect to (at least some) two-member sets of subcontrary claims $(2004,2005) .{ }^{38}$ Suppose a murder has been committed. There are 10 suspects. Each suspect has a probability of .1 of being the murderer, and each suspect has committed at least one crime: 2 suspects have committed robbery but not pickpocketing; 2 suspects have committed pickpocketing but not robbery; 6 suspects have committed robbery and pickpocketing. Let $S_{10}=\{r, p\}$, where:

$r \quad=$ The murderer has committed robbery;

$p \quad=$ The murderer has committed pickpocketing.

Let's call this case "Pickpocket." Each suspect has committed robbery or pickpocketing, so $r$ and $p$ are subcontrary claims (given the background information). Siebel holds that $S_{10}$ is coherent (given the high overlap between the set of robbers and the set of pickpocketers). $(\mathrm{CF})$, though, implies that $S_{10}$ is not coherent:

$$
\begin{array}{r}
C_{\mathrm{F}}\left(S_{10}\right)=\operatorname{mean}(\{f(r, p), f(p, r)\})=\frac{\frac{\operatorname{Pr}(p \mid r)-\operatorname{Pr}(p \mid \sim r)}{\operatorname{Pr}(p \mid r)+\operatorname{Pr}(p \mid \sim r)}+\frac{\operatorname{Pr}(r \mid p)-\operatorname{Pr}(r \mid \sim p)}{\operatorname{Pr}(r \mid p)+\operatorname{Pr}(r \mid \sim p)}}{2} \\
=\frac{\frac{.75-1}{.75+1}+\frac{.75-1}{.75+1}}{2}=-.143 .{ }^{39}
\end{array}
$$

In fact, (CF) implies that no two-member set of subcontrary claims is coherent.

(CR) implies that, as Siebel holds and contra (CF), $S_{10}$ is coherent. Observe that:

$$
C_{\mathrm{R}}\left(S_{10}\right)=\operatorname{mean}(\{a(r, p), a(p, r)\})=\frac{\operatorname{Pr}(r \mid p)+\operatorname{Pr}(p \mid r)}{2}=\frac{.75+.75}{2}=.75 \text {. }
$$

The table below compares the various accounts with respect to Pickpocket:

\footnotetext{
${ }^{38}$ Two claims are subcontraries just in case the falsity of the one claim entails the truth of the other.

39 Here and below at several points I have rounded for convenience. The decision procedure PrSAT developed by Branden Fitelson (in collaboration with Jason Alexander and Ben Blum) provides an extremely efficient means of obtaining or verifying results such as those explained in this subsection (4.2) and the next (4.3). See Fitelson (2008) for a description of PrSAT and some applications.
} 


\begin{tabular}{|c|c|}
\hline & Pickpocket \\
\hline$C_{\mathrm{S}}\left(S_{10}\right)$ & .938 \\
\hline$C_{\mathrm{O}}\left(S_{10}\right)$ & .6 \\
\hline$C_{\mathrm{DM}}\left(S_{10}\right)$ & -.05 \\
\hline$C_{\mathrm{F}}\left(S_{10}\right)$ & -.143 \\
\hline$C_{\mathrm{R}}\left(S_{10}\right)$ & .75 \\
\hline
\end{tabular}

(CS) and (CDM) agree with (CF) that $S_{10}$ is not coherent. (CO) agrees with Siebel and (CR) that $S_{10}$ is coherent.

It might seem that (CR) is incorrect in its implication that $S_{10}$ is coherent. For, it might seem that, at least with respect to two-member sets of claims, coherence is a matter of positive probabilistic relevance and incoherence is a matter of negative probabilistic relevance. $\operatorname{Pr}(r \mid$ $p)=.75<\operatorname{Pr}(r)=.8$, and $\operatorname{Pr}(p \mid r)=.75<\operatorname{Pr}(p)=.8$. So the claims in $S_{10}$ are negatively probabilistically relevant to each other. It might seem, then, that $S_{10}$ is incoherent, hence, contra (CR), is not coherent.

Recall that (CS) implies that whether a two-member set of claims is coherent hinges on whether the claims in the set are positively probabilistically relevant to each other (in that if the claims are positively probabilistically relevant to each other then the set is coherent, if the claims are probabilistically irrelevant to each other then the set is neither coherent nor incoherent, and if the claims are negatively probabilistically relevant to each other then the set is incoherent). It is no surprise then that (CS) agrees with (CF) that $S_{10}$ is not coherent.

The idea that, at least with respect to two-member sets of claims, coherence is a matter of positive probabilistic relevance and incoherence is a matter of negative probabilistic relevance has some initial plausibility. But, it runs counter to another idea with some initial plausibility - the idea that, at least with respect to two-member sets of claims, maximal coherence is a matter of mutual entailment (where the one claim entails the other claim, and where each claim has a probability greater than 0 ) and maximal incoherence is a matter of incompatibility (where the one claim entails the negation of the other claim). Suppose $S=\left\{p_{1}\right.$, $\left.p_{2}\right\}$. Suppose $p_{1}$ and $p_{2}$ are mutually entailing. Suppose $\operatorname{Pr}\left(p_{1}\right)=1=\operatorname{Pr}\left(p_{2}\right)$. Then, by the idea that maximal coherence is a matter of mutual entailment and maximal incoherence is a matter of incompatibility, it follows that $S$ is maximally coherent. But, by the idea that coherence is a matter of positive probabilistic relevance and incoherence is a matter of negative probabilistic relevance, it follows that, since $\operatorname{Pr}\left(p_{1} \mid p_{2}\right)=\operatorname{Pr}\left(p_{1}\right)=1$ and $\operatorname{Pr}\left(p_{2} \mid p_{1}\right)=\operatorname{Pr}\left(p_{2}\right)=1, S$ is neither coherent nor incoherent, hence is not maximally coherent. ${ }^{40}$

I prefer the idea that, at least with respect to two-member sets of claims, maximal coherence is a matter of mutual entailment and maximal incoherence is a matter of

\footnotetext{
${ }^{40}$ Meijs $(2006,237)$ gives an argument along these lines.
} 
incompatibility. ${ }^{41}$ One reason for this preference concerns sets of contradictory claims. Recall $S_{6}=\{f, \sim f\}$, where $f$ is the claim that $2+2=4$. This set, as with any set of contradictory claims, is incoherent, in fact, arguably, is maximally incoherent. But, since $\operatorname{Pr}(f)=1$ and $\operatorname{Pr}(\sim f)$ $=0$ and since, thus, it is not the case that $f$ and $\sim f$ are negatively probabilistically relevant to each other (for one thing, $\operatorname{Pr}(\sim f \mid f)=0=\operatorname{Pr}(\sim f)$ ), it follows from the idea that coherence is a matter of positive probabilistic relevance and incoherence is a matter of negative probabilistic relevance that it is not the case that $S_{6}$ is incoherent. By contrast, because $f$ and $\sim f$ are incompatible with each other, it follows from the idea that maximal coherence is a matter of mutual entailment and maximal incoherence is a matter of incompatibility that $S_{6}$ is incoherent, indeed, is maximally incoherent. ${ }^{42}$

(CF) is initially attractive because, in part, it implies each of the following: a set $S=\left\{p_{1}, p_{2}\right\}$ is maximally coherent if $p_{1}$ and $p_{2}$ are logically equivalent and $S$ is satisfiable;

a set $S=\left\{p_{1}, p_{2}\right\}$ is maximally incoherent if each of $\left\{p_{1}\right\},\left\{p_{2}\right\}$, and $\left\{p_{1}, p_{2}\right\}$ is unsatisfiable;

a set $S=\left\{p_{1}, p_{2}\right\}$ is coherent if $S$ is "positively dependent," where $S$ is positively dependent just in case (a) $f\left(p_{1}, p_{2}\right)>0$ and (b) $f\left(p_{2}, p_{1}\right)>0$;

a set $S=\left\{p_{1}, p_{2}\right\}$ is incoherent if $S$ is "negatively dependent," where $S$ is negatively dependent just in case (a) $f\left(p_{1}, p_{2}\right)<0$ and (b) $f\left(p_{2}, p_{1}\right)<0$.

(a) and (b) capture the idea that maximal coherence is a matter of logical equivalence and maximal incoherence is a matter of unsatisfiability. This idea is similar to the idea that

${ }^{41}$ In fact, I prefer the more general idea that for any set with two or more members maximal coherence is a matter of pairwise mutual entailment (where for each pair of claims in the set the one claim entails the other claim, and each claim has a probability greater than 0 ) and maximal incoherence is a matter of pairwise incompatibility (where for each pair of claims in the set the one claim entails the negation of the other claim).

${ }^{42}$ There are at least two further reasons for preferring the idea that maximal coherence is a matter of mutual entailment and maximal incoherence is a matter of incompatibility. First, if coherence is a matter of positive probabilistic relevance, it follows that no set of necessary truths is coherent. Hence no set of mathematical necessities is coherent, and no set of philosophical necessities is coherent (for example, no set of logical necessities is coherent), and so on. If, instead, maximal coherence is a matter of mutual entailment and maximal incoherence is a matter of incompatibility, it follows that all sets of necessary truths are coherent, indeed, maximally coherent. Second, if coherence is a matter of positive probabilistic relevance, it follows that there can be sets $S$ and $S^{*}$ such that the claims in $S$ are mutually entailing, the claims in $S^{*}$ are mutually entailing, and yet, because the prior probabilities of the claims in $S$ are lower than the prior probabilities of the claims in $S^{*}, S$ has a greater coherence value than $S^{*}$. If, instead, maximal coherence is a matter of mutual entailment and maximal incoherence is a matter of incompatibility, it follows that if the claims in $S$ are mutually entailing and the claims in $S^{*}$ are mutually entailing, then, regardless of the prior probabilities of the claims in $S$ and $S^{*}, S$ and $S^{*}$ have the same coherence value. For helpful discussion of (CF), (CS), (CO), and the issue of "prior-dependence," see Glass (2005). See, also, Fitelson (2003, sec. 2) and Siebel and Wolff (2008). 
maximal coherence is a matter of mutual entailment and maximal incoherence is a matter of incompatibility. (c) and (d), in turn, capture the idea that coherence is a matter of positive support (or confirmation) and incoherence is a matter of negative support. This idea is similar to the idea that coherence is a matter of positive probabilistic relevance and incoherence is a matter of negative probabilistic relevance. It turns out, though, that because (CF) implies each of (a)-(d) it yields some rather odd results.

This point is due to Meijs (2006). So too are the two remaining cases in this subsection: "Rabbit" and "Rabbit*." First, I shall set out the cases and show what (CF) implies with respect to them. Then I shall show what (CR) implies with respect to them.

Suppose there is a small island somewhere in the Pacific Ocean with a population of 102 rabbits: 100 of the rabbits are grey and have two ears; 1 of the rabbits is grey and has one ear; 1 of the rabbits is albino and has two ears. Let this be Situation I. Suppose, instead, 100 of the rabbits are grey and have two ears, and 2 of the rabbits are albino and have one ear. Let this be Situation II. Let $S_{11}=\{g, e\}$, where:

$$
\begin{array}{ll}
g & =\text { This rabbit is grey; } \\
e & =\text { This rabbit has two ears. }
\end{array}
$$

This case is Rabbit. (CF) implies that in Situation I, where $S_{11}$ is negatively dependent, $S_{11}$ is incoherent:

$$
\begin{array}{r}
C_{\mathrm{F}}\left(S_{11}\right)=\operatorname{mean}(\{f(g, e), f(e, g)\})=\frac{\frac{\operatorname{Pr}(e \mid g)-\operatorname{Pr}(e \mid \sim g)}{\operatorname{Pr}(e \mid g)+\operatorname{Pr}(e \mid \sim g)}+\frac{\operatorname{Pr}(g \mid e)-\operatorname{Pr}(g \mid \sim e)}{\operatorname{Pr}(g \mid e)+\operatorname{Pr}(g \mid \sim e)}}{2} \\
=\frac{\frac{100 / 101-1}{100 / 101+1}+\frac{100 / 101-1}{100 / 101+1}}{2}=-.005 .
\end{array}
$$

Things are quite different with respect to Situation II. (CF) implies that in Situation II, where $g$ and $e$ are logically equivalent (given the background information) and $S_{11}$ is satisfiable, $S_{11}$ is maximally coherent:

$$
C_{\mathrm{F}}\left(S_{11}\right)=\operatorname{mean}(\{f(g, e), f(e, g)\})=\frac{1+1}{2}=1 .
$$

(CF) thus implies that $S_{11}$ is incoherent in Situation I and is maximally coherent in Situation II, hence has a very much greater coherence value in Situation II. This is an odd result, given that the two situations differ hardly at all (in terms of rabbits and their properties). $S_{11}$, it seems, is coherent in Situation I, and, what is crucial, has just a slightly greater coherence value in Situation II.

This result, it turns out, does not depend on the number of two-eared grey rabbits. Suppose there are 10 million rabbits on the island, where all but 2 of the rabbits are grey and have two ears, 1 of the other 2 rabbits is albino and has two ears, and the 1 remaining rabbit is grey and has one ear. Let this be Situation I. Suppose instead all but 2 of the rabbits are grey and have two ears, and the other 2 rabbits are albino and have one ear. Let this be Situation II. This case is Rabbit*. In Situation I $C_{\mathrm{F}}\left(S_{11}\right)<0$ : 


$$
\begin{aligned}
C_{\mathrm{F}}\left(S_{11}\right)=\operatorname{mean}(\{f(g, e), f(e, g)\})=\frac{\frac{\operatorname{Pr}(e \mid g)-\operatorname{Pr}(e \mid \sim g)}{\operatorname{Pr}(e \mid g)+\operatorname{Pr}(e \mid \sim g)}+\frac{\operatorname{Pr}(g \mid e)-\operatorname{Pr}(g \mid \sim e)}{\operatorname{Pr}(g \mid e)+\operatorname{Pr}(g \mid \sim e)}}{2} \\
=\frac{\frac{9999998 / 9999999-1}{9999998 / 9999999+1}+\frac{9999998 / 99999999-1}{9999998 / 9999999+1}}{2}=-.00000005 .
\end{aligned}
$$

In Situation II $C_{\mathrm{F}}\left(S_{11}\right)=1$ :

$$
C_{\mathrm{F}}\left(S_{11}\right)=\operatorname{mean}(\{f(g, e), f(e, g)\})=\frac{1+1}{2}=1 .
$$

So, (CF) yields the odd result that $S_{11}$ is incoherent in Situation I, is maximally coherent in Situation II, and thus has a very much greater coherence value in Situation II.

How does (CR) do with Rabbit and Rabbit*? In Rabbit in Situation I:

$$
C_{\mathrm{R}}\left(S_{11}\right)=\operatorname{mean}(\{a(g, e), a(e, g)\})=\frac{\operatorname{Pr}(g \mid e)+\operatorname{Pr}(e \mid g)}{2}=\frac{\frac{100}{101}+\frac{100}{101}}{2}=.990 .
$$

In Rabbit in Situation II:

$$
C_{\mathrm{R}}\left(S_{11}\right) \quad=\quad \operatorname{mean}(\{a(g, e), a(e, g)\})=\frac{1+1}{2}=1 .
$$

In Rabbit* in Situation I:

$$
\begin{array}{r}
C_{\mathrm{R}}\left(S_{11}\right)=\operatorname{mean}(\{a(g, e), a(e, g)\})=\frac{\operatorname{Pr}(g \mid e)+\operatorname{Pr}(e \mid g)}{2}=\frac{\frac{9999998}{999999}+\frac{9999998}{9999999}}{2} \\
=.9999999 .
\end{array}
$$

In Rabbit* in Situation II:

$$
C_{\mathrm{R}}\left(S_{11}\right)=\operatorname{mean}(\{a(g, e), a(e, g)\})=\frac{1+1}{2}=1 .
$$

$S_{11}$ is thus coherent, indeed, highly coherent, in Situation I in Rabbit, and is slightly more coherent in Situation II in Rabbit. The same is true with respect to Rabbit*.

The table below compares the various accounts with respect to Rabbit and Rabbit*: 


\begin{tabular}{|c|c|c|c|c|}
\hline & \multicolumn{2}{|c|}{ Rabbit } & \multicolumn{2}{c|}{ Rabbit* } \\
\hline & Situation I & Situation II & Situation I & Situation II \\
\hline$C_{\mathrm{S}}\left(S_{11}\right)$ & .9999 & 1.02 & .99999999999999 & 1.0000002 \\
\hline$C_{\mathrm{O}}\left(S_{11}\right)$ & .980 & 1 & .9999998 & 1 \\
\hline$C_{\mathrm{DM}}\left(S_{11}\right)$ & -.0001 & .020 & -.00000000000001 & .0000002 \\
\hline$C_{\mathrm{F}}\left(S_{11}\right)$ & -.005 & 1 & -.00000005 & 1 \\
\hline$C_{\mathrm{R}}\left(S_{11}\right)$ & .990 & 1 & .9999999 & 1 \\
\hline
\end{tabular}

(CS), (CO), and (CDM) agree with (CR) in implying that $S_{11}$ 's coherence value is just slightly greater in Situation II in Rabbit than in Situation I in Rabbit, and is just slightly greater in Situation II in Rabbit* than in Situation I in Rabbit*. (CO), but neither (CS) nor (CDM), further agrees with (CR) in implying that $S_{11}$ 's coherence value is high both in Situation I in Rabbit and in Situation I in Rabbit*.

The claims in $S_{10}$ are negatively probabilistically relevant to each other. Likewise, the claims in $S_{11}$ both in Situation I in Rabbit and in Situation I in Rabbit* are negatively probabilistically relevant to each other. I turn now to a case, "Samurai Sword," where the claims in the set at issue are positively probabilistically relevant to each other. I take the case from Douven and Meijs $(2007,414)$.

\subsubsection{Samuai Sword}

Suppose a murder has been committed on a street in a city with 10,000,000 inhabitants. 1050 of the 10,000,000 inhabitants are Japanese and do not own a Samurai sword, 1050 of the $10,000,000$ inhabitants own a Samurai sword and are not Japanese, and just 9 of the $10,000,000$ inhabitants are Japanese and own a Samurai sword. The murderer lives in the city and each person in the city is equally likely to be the murderer. Let this be Situation I. Suppose, instead, the murderer lives on the street on which the body was found, 100 people live on that street, 1 of the 100 people is Japanese and does not own a Samurai sword, 1 of the 100 people owns a Samurai sword and is not Japanese, and 9 of the 100 people are Japanese and own a Samurai sword. Let this be Situation II. Let $S_{12}=\{j, o\}$, where:

$$
\begin{array}{ll}
j & =\text { The murderer is Japanese; } \\
o & =\text { The murderer owns a Samurai sword. }
\end{array}
$$

Intuitively, $S_{12}$ has a greater coherence value in Situation II than in Situation I, indeed, has a much greater coherence value in Situation II than in Situation I. Furthermore, intuitively, $S_{12}$ is very far from being maximally coherent in Situation I.

(CF), though, implies that $S_{12}$ has a just slightly greater coherence value in Situation II than in Situation I, and that $S_{12}$ is nearly maximally coherent in Situation I. In Situation I: 


$$
\begin{array}{r}
C_{\mathrm{F}}\left(S_{12}\right)=\operatorname{mean}(\{f(j, o), f(o, j)\})=\frac{\frac{\operatorname{Pr}(o \mid j)-\operatorname{Pr}(o \mid \sim j)}{\operatorname{Pr}(o \mid j)+\operatorname{Pr}(o \mid \sim j)}+\frac{\operatorname{Pr}(j \mid o)-\operatorname{Pr}(j \mid \sim o)}{\operatorname{Pr}(j \mid o)+\operatorname{Pr}(j \mid \sim o)}}{2} \\
=\frac{\frac{9 / 1059-1050 / 9998941}{9 / 1059+1050 / 9998941}+\frac{9 / 1059-1050 / 9998941}{9 / 1059+1050 / 9998941}}{2}=.97559 .
\end{array}
$$

In Situation II:

$$
\begin{array}{r}
C_{\mathrm{F}}\left(S_{12}\right)=\operatorname{mean}(\{f(j, o), f(o, j)\})=\frac{\frac{\operatorname{Pr}(o \mid j)-\operatorname{Pr}(o \mid \sim j)}{\operatorname{Pr}(o \mid j)+\operatorname{Pr}(o \mid \sim j)}+\frac{\operatorname{Pr}(j \mid o)-\operatorname{Pr}(j \mid \sim o)}{\operatorname{Pr}(j \mid o)+\operatorname{Pr}(j \mid \sim o)}}{2} \\
=\frac{\frac{9 / 10-1 / 90}{9 / 10+1 / 90}+\frac{9 / 10-1 / 90}{9 / 10+1 / 90}}{2}=.97561 .
\end{array}
$$

(CR) does well with Samurai Sword. In Situation I:

$$
\begin{aligned}
& C_{\mathrm{R}}\left(S_{12}\right)=\operatorname{mean}(\{a(j, o), a(o, j)\})=\frac{\operatorname{Pr}(j \mid o)+\operatorname{Pr}(o \mid j)}{2}=\frac{9 / 1059+9 / 1059}{2} \\
&=.008 .
\end{aligned}
$$

In Situation II:

$$
C_{\mathrm{R}}\left(S_{12}\right)=\operatorname{mean}(\{f(j, o), f(o, j)\})=\frac{\operatorname{Pr}(j \mid o)+\operatorname{Pr}(o \mid j)}{2}=\frac{9 / 10+9 / 10}{2}=.9 .
$$

(CR) thus implies that $S_{12}$ has a much greater coherence value in Situation II than in Situation I, and that $S_{12}$ is very far from being maximally coherent in Situation I.

The table below compares the various accounts with respect to Samurai Sword:

\begin{tabular}{|c|c|c|}
\hline & \multicolumn{2}{|c|}{ Samurai Sword } \\
\hline & Situation I & Situation II \\
\hline$C_{\mathrm{S}}\left(S_{12}\right)$ & 80.251 & 9 \\
\hline$C_{\mathrm{O}}\left(S_{12}\right)$ & .004 & .818 \\
\hline$C_{\mathrm{DM}}\left(S_{12}\right)$ & .008 & .8 \\
\hline$C_{\mathrm{F}}\left(S_{12}\right)$ & .97559 & .97561 \\
\hline$C_{\mathrm{R}}\left(S_{12}\right)$ & .008 & .9 \\
\hline
\end{tabular}

(CO) and (CDM) agree with (CR) in implying that $S_{12}$ has a much greater coherence value in Situation II than in Situation I, and that $S_{12}$ is very far from being maximally coherent in Situation I. (CS), contra (CR) and each of the other accounts, implies that $S_{12}$ has a lesser coherence value in Situation II than in Situation I. 


\subsubsection{Some additional test cases}

I now want to consider two additional test cases: "Tweety" and "Tweety*."

Luc Bovens and Stephan Hartmann (2003, 44-45, 50) argue that (CO) is counterintuitive. Let $S_{13}=\{b, g\}$ and $S_{14}=\{b, g, p\}$, where:
$b \quad=\quad$ Tweety is a bird;
$g \quad=\quad$ Tweety is a ground dweller;
$p \quad=\quad$ Tweety is a penguin.

Suppose the probability distribution:

\begin{tabular}{ccccccccc}
\hline$b$ & $g$ & $p$ & $\mathrm{Pr}$ & & $b$ & $g$ & $p$ & $\mathrm{Pr}$ \\
\cline { 1 - 3 } \cline { 5 - 8 } $\mathrm{T}$ & $\mathrm{T}$ & $\mathrm{T}$ & .01 & & $\mathrm{~F}$ & $\mathrm{~T}$ & $\mathrm{~T}$ & 0 \\
$\mathrm{~T}$ & $\mathrm{~T}$ & $\mathrm{~F}$ & 0 & & $\mathrm{~F}$ & $\mathrm{~T}$ & $\mathrm{~F}$ & .49 \\
$\mathrm{~T}$ & $\mathrm{~F}$ & $\mathrm{~T}$ & 0 & & $\mathrm{~F}$ & $\mathrm{~F}$ & $\mathrm{~T}$ & 0 \\
$\mathrm{~T}$ & $\mathrm{~F}$ & $\mathrm{~F}$ & .49 & & $\mathrm{~F}$ & $\mathrm{~F}$ & $\mathrm{~F}$ & .01 \\
\hline
\end{tabular}

This case is Tweety. Intuitively, $S_{14}$ 's coherence value is greater than $S_{13}$ 's coherence value. (CO), however, implies that $S_{14}$ 's coherence value is equal to $S_{13}$ 's coherence value:

$$
\begin{aligned}
C_{\mathrm{O}}\left(S_{13}\right) & =\frac{\operatorname{Pr}(b \wedge g)}{\operatorname{Pr}(b \vee \mathrm{g})}=\frac{.01}{.99} \\
C_{\mathrm{O}}\left(S_{14}\right) & =\frac{\operatorname{Pr}(b \wedge g \wedge p)}{\operatorname{Pr}(b \vee \mathrm{g} \vee \mathrm{p})}=\frac{.01}{.99}
\end{aligned}
$$

Douven and Meijs (2007, 416-417) argue that things are even worse for (CO). Suppose a slightly different probability distribution (on which the probability that Tweety is a ground-

\begin{tabular}{|c|c|c|c|c|c|c|c|}
\hline$b$ & $g$ & $p$ & $\operatorname{Pr}$ & $b$ & $g$ & $p$ & $\operatorname{Pr}$ \\
\hline $\mathrm{T}$ & $\mathrm{T}$ & $\mathrm{T}$ & .01 & $\mathrm{~F}$ & $\mathrm{~T}$ & $\mathrm{~T}$ & 0 \\
\hline $\mathrm{T}$ & $\mathrm{T}$ & $\mathrm{F}$ & .000001 & $\mathrm{~F}$ & $\mathrm{~T}$ & $\mathrm{~F}$ & .49 \\
\hline $\mathrm{T}$ & $\mathrm{F}$ & $\mathrm{T}$ & 0 & $\mathrm{~F}$ & $\mathrm{~F}$ & $\mathrm{~T}$ & 0 \\
\hline $\mathrm{T}$ & $\mathrm{F}$ & $\mathrm{F}$ & .49 & $\mathrm{~F}$ & $\mathrm{~F}$ & $\mathrm{~F}$ & 009999 \\
\hline
\end{tabular}
dwelling bird but not a penguin, for example, an ostrich, is greater than 0 but very small):

This case is Tweety*. Intuitively, $S_{14}$ 's coherence value is greater than $S_{13}$ 's coherence value. But, if (CO) is correct, it follows that $S_{14}$ 's coherence value is less than $S_{13}$ 's coherence value: 


$$
\begin{aligned}
& C_{\mathrm{O}}\left(S_{13}\right) \quad=\frac{\operatorname{Pr}(b \wedge g)}{\operatorname{Pr}(b \vee \mathrm{g})}=\frac{.010001}{.990001} \\
& C_{\mathrm{O}}\left(S_{14}\right) \quad=\frac{\operatorname{Pr}(b \wedge g \wedge p)}{\operatorname{Pr}(b \vee \mathrm{g} \vee \mathrm{p})}=\frac{.01}{.990001} .
\end{aligned}
$$

(CR) does well with Tweety and Tweety*. In Tweety, $C_{\mathrm{R}}\left(S_{13}\right)<C_{\mathrm{R}}\left(S_{14}\right)$ :

$$
\begin{aligned}
& C_{\mathrm{R}}\left(S_{13}\right)=\operatorname{mean}(\{a(b, g), a(g, b)\})=\frac{\operatorname{Pr}(b \mid g)+\operatorname{Pr}(g \mid b)}{2}=\frac{.02+.02}{2}=.02 ; \\
& C_{\mathrm{R}}\left(S_{14}\right)=\operatorname{mean}(\{a(b, g)+a(b, p)+a(g, b)+a(g, p)+a(p, b)+a(p, g)+a(b, g \wedge \\
& p)+a(g, b \wedge p)+a(p, b \wedge g)+a(b \wedge g, p)+a(b \wedge p, g)+a(g \wedge p, b)\}) \\
& \operatorname{Pr}(b \mid g)+1+\operatorname{Pr}(g \mid b)+1 \\
& +\operatorname{Pr}(p \mid b)+\operatorname{Pr}(p \mid g)+1+1 \quad .02+1+.02+1 \\
& =\frac{+1+1+\operatorname{Pr}(b \wedge p \mid g)+\operatorname{Pr}(g \wedge p \mid b)}{12}=\frac{+1+1+.02+.02}{12}=.51 \text {. }
\end{aligned}
$$

In Tweety*, $C_{\mathrm{R}}\left(S_{13}\right)<C_{\mathrm{R}}\left(S_{14}\right)$ :

$$
\begin{aligned}
& C_{\mathrm{R}}\left(S_{13}\right)=\operatorname{mean}(\{a(b, g), a(g, b)\})=\frac{\operatorname{Pr}(b \mid g)+\operatorname{Pr}(g \mid b)}{2}=\frac{.020002+.020002}{2} \\
& =.020002 \\
& C_{\mathrm{R}}\left(S_{14}\right)=\operatorname{mean}(\{a(b, g)+a(b, p)+a(g, b)+a(g, p)+a(p, b)+a(p, g)+a(b, g \wedge \\
& p)+a(g, b \wedge p)+a(p, b \wedge g)+a(b \wedge g, p)+a(b \wedge p, g)+a(g \wedge p, b)\}) \\
& \operatorname{Pr}(b \mid g)+1+\operatorname{Pr}(g \mid b)+1 \\
& +\operatorname{Pr}(p \mid b)+\operatorname{Pr}(p \mid g)+1+1 \quad .020002+1+.020002+1 \\
& =\frac{+\operatorname{Pr}(p \mid b \wedge g)+1+\operatorname{Pr}(b \wedge p \mid g)+\operatorname{Pr}(g \wedge p \mid b)}{12}=\frac{+.9999+1+.02+.02}{12}=.509992 \text {. }
\end{aligned}
$$

The table below compares the various accounts with respect to Tweety and Tweety*: 


\begin{tabular}{|l|c|c|}
\hline & Tweety & Tweety* \\
\hline$C_{\mathrm{S}}\left(S_{13}\right)$ & .04 & .040004 \\
\hline$C_{\mathrm{S}}\left(S_{14}\right)$ & 4 & 3.99998 \\
\hline$C_{\mathrm{O}}\left(S_{13}\right)$ & $\frac{.01}{.99}$ & $\frac{.010001}{.990001}$ \\
\hline$C_{\mathrm{O}}\left(S_{14}\right)$ & $\frac{.01}{.99}$ & $\frac{.01}{.990001}$ \\
\hline$C_{\mathrm{DM}}\left(S_{14}\right)$ & -.48 & -.479999 \\
\hline$C_{\mathrm{DM}}\left(S_{14}\right)$ & .255 & .254991 \\
\hline$C_{\mathrm{F}}\left(S_{13}\right)$ & -.96 & -.959996 \\
\hline$C_{\mathrm{F}}\left(S_{14}\right)$ & .4526126 & .4526128 \\
\hline$C_{\mathrm{R}}\left(S_{13}\right)$ & .02 & .020002 \\
\hline$C_{\mathrm{R}}\left(S_{14}\right)$ & .51 & .509992 \\
\hline
\end{tabular}

(CS), (CDM), and (CF) all agree with (CR) that $S_{14}$ 's coherence value is greater than $S_{13}$ 's coherence value both in Tweety and in Tweety*.

\subsection{Summary}

In 4.1, I gave some problem cases for (CS), (CO), and (CDM), where each of the cases is unproblematic for (CR). In 4.2, I gave some problem cases for (CF), where each of the cases is unproblematic for (CR). In 4.3, I gave two additional test cases neither of which is problematic for (CR). It does not follow, of course, that (CR) is correct or even likely to be correct; more test cases need to be examined. But the results are at least suggestive. ${ }^{43}$

\section{5 (CR) and the Problem of Justified Inconsistent Beliefs}

I began the paper with the question of whether coherence is necessary for (epistemic) justification, in that one's beliefs are justified only if one's belief system is coherent. Standard varieties of coherentism imply that the answer is affirmative. In this section I relate (CR) to an argument for rejecting this answer and, in turn, for rejecting standard varieties of coherentism.

${ }^{43}$ Certain of the accounts, even if inadequate as accounts of coherence, can be useful nonetheless, for example, in contexts of confirmation. See Dietrich and Moretti (2005), for discussion of $(\mathrm{CF}),(\mathrm{CO})$, and $(\mathrm{CS})$ and the transmission of confirmation. 


\subsection{Coherentism}

Coherentism is distinct from foundationalism, social contextualism, and infinitism in that, inter alia, coherentism requires (for justification) a "circular" chain of implication (or evidential support):

Circular Chain of Implication (CCI): $S$ 's belief in $p$ is justified only if (i) $S$ 's belief in $p$ is implied (deductively or inductively) by certain of her other beliefs, which themselves are implied by certain of her other beliefs, and so on, and (ii) this chain of evidential support circles back around at some point and does not continue on ad infinitum with new belief after new belief.

(CCI) should be understood so that (ii) does not require that the chain of implication in question literally take the shape of a circle, where, say, $S$ 's belief in $p$ is implied by her belief in $q$, which is implied by her belief in $r$, which is implied by her belief in $p$. It would be enough if, say, (a) $S$ 's belief in $p$ were implied by her belief in $q$ together with her belief in $r$, (b) $S$ 's belief in $q$ were implied by her belief in $p$ together with her belief in $r$, and (c) $S$ 's belief in $r$ were implied by her belief in $p$ together with her belief in $q{ }^{44}$

Coherentism comes in many varieties. Here is a fairly simple variety:

$S$ 's belief in $p$ is justified if and only if (i) $S$ 's belief in $p$ is implied by certain of her other beliefs, which themselves are implied by certain of her other beliefs, and so on, (ii) this chain of implication circles back around at some point and does not continue on ad infinitum, and (iii) $S$ 's belief system is coherent.

(C1) should be understood so that whether $S$ 's belief system is coherent is determined by whether the set of claims believed by $S$ is coherent, and so that $S$ 's belief in $p$, if justified, is justified by (that is, is made justified by) not certain of her other beliefs, but by the fact that (i)-(iii) are satisfied. ${ }^{45}$

The argument set out in the next subsection is spelled out in terms of $(\mathrm{C} 1)$. But the argument can be generalized so that it applies to other varieties of coherentism. For example, the argument can be generalized so that it applies to varieties of coherentism on which what needs to be coherent is $S$ 's system of beliefs and perceptual experiences. ${ }^{46}$

${ }^{44}$ For discussion of the "regress problem" and foundationalism, social contextualism, infinitism, and coherentism, and for references, see Cling (2008). It might be best to allow for varieties of coherentism on which some justification is noninferential, and thus on which it is not required for justification that (CCI) be satisfied. See Lycan (2012) and Poston (2012).

45 A circular chain of implication should not be confused with a circular chain of justification. Coherentists (of the sort I have in mind) deny that justification is transferred between beliefs. Coherentists hold that justification is holistic: Beliefs are justified together when the requisite conditions are satisfied. For further discussion of this and related issues, see Roche (2012b).

${ }^{46}$ For discussion of varieties of coherentism of this sort, and for references, see Roche (2012b). 
5.2 The Problem of Justified Inconsistent beliefs

The Problem of Justified Inconsistent Beliefs (see Foley 1979) can be put as follows. (C1) implies:

(A) $\quad S$ 's belief in $p$ is justified only if $S$ 's belief system is coherent.

It seems obvious that:

(B) $\quad S$ 's belief system is coherent only if $S$ 's belief system is consistent. ${ }^{47}$

(A) and (B) together imply:

(C) $\quad S$ 's belief in $p$ is justified only if $S$ 's belief system is consistent.

(C) implies that if $S$ 's belief system is inconsistent, then all of $S$ 's beliefs are unjustified. ${ }^{48}$ But surely this implication is false. Consider, again, $S_{8}=\left\{p_{1}, \ldots, p_{n}\right\}$ and $S_{9}=\left\{p_{1}, \ldots, p_{n}, p_{n+1}\right\}$, where $S_{8}$ is very large and highly coherent (on any account of coherence), and where $p_{n+1}$ is the necessary falsehood that $3^{8}$ is greater than 6562. Suppose Smith believes (all and only) the claims in $S_{8}$. Smith is listening to his math professor, who, as it turns out, is quite tired. Smith's math professor utters $p_{n+1}$. Smith knows his math professor to be highly reliable on matters mathematical, and so comes to believe $p_{n+1}$. Smith thus comes to believe the claims in $S_{9}$. Let's call this case "Tired Math Professor." Smith's belief system (when he believes the claims in $S_{9}$ ) is inconsistent, hence by (C) it follows that all of Smith's beliefs are unjustified. And yet, on certain ways of filling in the details, at least some of Smith's beliefs, e.g., at least some of Smith's perceptual beliefs, are justified. So, (C) is false. Therefore, given (B), it follows that $(\mathrm{A})$ is false, hence $(\mathrm{C} 1)$ is false. Or so the argument goes. ${ }^{49}$

Coherentists, let's suppose, should want to reject (C) and so should want to reject (A) or (B). The question is whether coherentists have a principled means of doing so.

\section{$5.3(\mathrm{CR})$ and inconsistency}

I showed above (4.1.3) that (CR) allows that $S_{9}$ can have a coherence value greater than the minimum value of 0 . Perhaps (CR) also allows that $S_{9}$ can have a coherence value greater than .5. If so, coherentists can reject (B) on the grounds that (CR) is correct and (CR) implies that (B) is false. Further, coherentists can agree that at least some of Smith's beliefs, e.g., at least some of his perceptual beliefs, are justified. Does (CR) allow that $S_{9}$ can have a coherence value greater than .5 ?

${ }^{47}$ (B) should be understood so that whether $S$ 's belief system is consistent is determined by whether the set of claims believed by $S$ is consistent.

${ }^{48}$ (C), like (A), is fully general and so applies to all of $S$ 's beliefs.

49 There is a second version of the Problem of Justified Inconsistent Beliefs pertaining to lottery-style cases. See Kvanvig (2012) for an explanation of the problem and an attempted solution. Eric Senseman (2010), a former undergraduate student of mine (at Texas Christian University), considers a variant of (CR) and how that variant relates to the problem. 
The answer, unfortunately for proponents of views such as (C1), is negative. Suppose $C_{\mathrm{R}}\left(S_{8}\right)$ has the maximum value of 1 , so each of the confirmation values in $S_{8} * * * *$ is equal to 1 . Then, since (i) $a\left(\wedge S^{\prime}, \wedge S^{\prime \prime}\right)=0$ for any $a\left(\wedge S^{\prime}, \wedge S^{\prime \prime}\right)$ such that (a) $a\left(\wedge S^{\prime}, \wedge S^{\prime \prime}\right)$ is a member of $S_{9} * * * *$ and (b) $\wedge S^{\prime}$ or $\wedge S^{\prime}$ ' involves $p_{n+1},{ }^{50}$ (ii) $C_{\mathrm{R}}\left(S_{9}\right)$ is the mean of $3^{n+1}-2^{n+2}+1$ confirmation values, ${ }^{51}$ (iii) each of the confirmation values in $S_{9} * * * *$ but not in $S_{8} * * * *$ is equal to 0 , and (iv) there are $3^{n}-2^{n+1}+1$ remaining confirmation values in $S_{9} * * * *$ and each one is equal to 1 , it follows that:

$C_{\mathrm{R}}\left(S_{9}\right) \quad=\frac{3^{n}-2^{n+1}+1}{3^{n+1}-2^{n+2}+1}$.

$\frac{3^{n}-2^{n+1}+1}{3^{n+1}-2^{n+2}+1}$ approaches $\frac{1}{3}$ very quickly as $n$ increases. Let $n=2$, so $S_{8}=\left\{p_{1}, p_{2}\right\}$ and $S_{9}=$ $\left\{p_{1}, p_{2}, p_{3}\right\}$. Then:

$C_{\mathrm{R}}\left(S_{9}\right)$

$$
=\frac{3^{2}-2^{3}+1}{3^{3}-2^{4}+1}=\frac{9-8+1}{27-16+1}=\frac{2}{12} \approx .167 .
$$

This can also be seen by verifying that:

$$
\begin{aligned}
C_{\mathrm{R}}\left(S_{9}\right)= & \operatorname{mean}\left(\left\{a\left(p_{1}, p_{2}\right)+a\left(p_{1}, p_{3}\right)+a\left(p_{2}, p_{1}\right)+a\left(p_{2}, p_{3}\right)+a\left(p_{3}, p_{1}\right)+a\left(p_{3}, p_{2}\right)\right.\right. \\
& +a\left(p_{1}, p_{2} \wedge p_{3}\right)+a\left(p_{2}, p_{1} \wedge p_{3}\right)+a\left(p_{3}, p_{1} \wedge p_{2}\right)+a\left(p_{1} \wedge p_{2}, p_{3}\right)+a\left(p_{1} \wedge\right. \\
& \left.\left.\left.p_{3}, p_{2}\right)+a\left(p_{2} \wedge p_{3}, p_{1}\right)\right\}\right) \\
& =\frac{1+0+1+0+0+0+0+0+0+0+0+0}{12}=\frac{2}{12} \approx .167 .
\end{aligned}
$$

When $n=3, C_{\mathrm{R}}\left(S_{9}\right)=\frac{12}{50}=.24$. When $n=4, C_{\mathrm{R}}\left(S_{9}\right)=\frac{50}{180} \approx .278$. When $n=5, C_{\mathrm{R}}\left(S_{9}\right)=\frac{180}{602} \approx$ $.299 \ldots$ When $n=10, C_{\mathrm{R}}\left(S_{9}\right)=\frac{57002}{173052} \approx .329$. But, regardless of the size of $n$ (though given the constraint that $2 \leq n<\infty$ where $n \in \mathbb{N}), \frac{3^{n}-2^{n+1}+1}{3^{n+1}-2^{n+2}+1}<\frac{1}{3}<.5$. ${ }^{52}$ So, regardless of the size of $n$, it follows that $C_{\mathrm{R}}\left(S_{9}\right)<.5$. Thus, since $C_{\mathrm{R}}\left(S_{9}\right)<.5$ in the best case where $C_{\mathrm{R}}\left(S_{8}\right)=1$, it follows that $C_{\mathrm{R}}\left(S_{9}\right)<.5$ in lesser cases where $C_{\mathrm{R}}\left(S_{8}\right)<1$.

The lesson is that, though (CR) allows that $S_{9}$ can have a coherence value greater than the minimum value of $0,(\mathrm{CR})$ does not allow that $S_{9}$ can have a coherence value greater than 5 . (CR), thus, does not provide coherentists with a principled means of answering the Problem of Justified Inconsistent Beliefs.

${ }^{50}$ If $\wedge S^{\prime}$ involves $p_{n+1}, \wedge S^{\prime}, \vDash \sim \wedge S^{\prime}$. If $\wedge S^{\prime}$, involves $p_{n+1}, \wedge S^{\prime}, \vDash \sim \wedge S^{\prime}$.

${ }^{51}$ Recall (from 3.3) that where $S=\left\{p_{1}, \ldots, p_{n}\right\}, C_{\mathrm{X}}(S)$ is the mean of $3^{n}-2^{n+1}+1$ confirmation values. Thus where $S=\left\{p_{1}, \ldots, p_{n}, p_{n+1}\right\}, C_{\mathrm{X}}(S)$ is the mean of $3^{n+1}-2^{n+2}+1$ confirmation values.

52 This follows from the fact that (i) $\frac{3^{n}-2^{n+1}+1}{3^{n+1}-2^{n+2}+1}<\frac{1}{3}$ when $n=2$, (ii) $\frac{3^{n}-2^{n+1}+1}{3^{n+1}-2^{n+2}+1}$ is a strictly increasing function of $n$ (given the constraint that $2 \leq n<\infty$ where $n \in \mathbb{N}$ ), and (iii) $\lim _{n \rightarrow \infty} \frac{3^{n}-2^{n+1}+1}{3^{n+1}-2^{n+2}+1}=\frac{1}{3}$. 
I leave it for further inquiry whether one can accept a probabilistic account of coherence and yet avoid (C) by rejecting (B). ${ }^{53}$ I want to consider whether coherentists can accept (CR) and, still, avoid (C) by rejecting (A). I aim to show that the answer is affirmative.

\subsection{Nonglobal coherentism}

Proponents of $(\mathrm{C} 1)$ are "globalist" coherentists, in that they require that $S$ 's belief system as a whole be coherent. Coherentists per se, however, need not be globalists. Coherentists can be "nonglobalists" and hold that justification requires not that $S$ 's belief system as a whole be coherent, but that a certain perhaps proper subset of $S$ 's belief system be coherent. ${ }^{54}$ Consider the view:

$S$ 's belief in $p$ is justified if and only if (i) $S$ 's belief in $p$ is implied by certain of her other beliefs, which themselves are implied by certain of her other beliefs, and so on, (ii) this chain of implication circles back around at some point and does not continue on ad infinitum, and (iii) the $p$-subset of $S$ 's belief system is coherent.

The " $p$-subset" of $S$ 's belief system is the subset of his belief system relevant to the justification of his belief in $p$. If not all of $S$ 's belief system is relevant to the justification of his belief in $p$, then the $p$-subset of $S$ 's belief system is a proper subset of his belief system, and so (iii) in (C2) can be satisfied even if $S$ 's belief system as a whole is not coherent. (C2) thus opens the way for coherentists to reject (C), along with (A), and allow for cases in which $S$ 's belief system as a whole is inconsistent, and incoherent, and yet certain of $S$ 's beliefs are justified. $^{55}$

Let's return to Tired Math Professor. Suppose Smith's belief in $p_{1}$ is a perceptual belief. Suppose, as seems plausible, Smith's belief in $p_{n+1}$ is not a member of the $p_{1}$-subset of Smith's belief system. Suppose (CR) is correct, and by (CR) the $p_{1}$-subset of Smith's belief system is coherent. Suppose, finally, (i) and (ii) in (C2) are satisfied. Then, even though Smith's belief system as a whole is inconsistent, (C2) implies that Smith's belief in $p_{1}$ is justified.

A difficult question for proponents of a view such as (C2) is of which of $S$ 's beliefs are in the $p$-subset of his belief system. Here I will not try to answer that question. ${ }^{56}$ The main point is just that, by accepting a view such as (C2), coherentists can accept (CR) and still allow that in cases such as Tired Math Professor certain of the subject's beliefs are justified.

${ }^{53}$ One possibility would be to understand probability so that $\operatorname{Pr}(p)$ can be greater than 0 even if $p$ is a necessary falsehood (and so that $\operatorname{Pr}(p)$ can be less than 1 even if $p$ is a necessary truth). For relevant discussion, see Chalmers (2011), Douven and Meijs (2007, sec. 5.1), Garber (1983), and Swinburne (1973, Ch. IV). See, also, Kvanvig (2012, sec. 2) and Lycan (1996, sec. VII; 2012, sec. 7).

${ }^{54}$ See Lycan $(1996,2012)$ and Olsson (1997).

${ }^{55}$ For discussion of an alternative way for coherentists to reject $(\mathrm{C})$, even when $(\mathrm{C})$ is construed not in terms of the notion of belief but in terms of the notion of acceptance, see Lehrer (1999). Cf. Olsson (1999).

${ }^{56}$ I take up the question elsewhere (2011). See, too, Kvanvig (2012, sec. 2). 


\section{Conclusion}

I have developed a probabilistic account of coherence, (CR), and argued that at least in certain respects it is preferable to Douven and Meijs's account, (CDM), Fitelson's account, (CF), Olsson's account, (CO), and Shogenji's account, (CS). Further, I have argued that (CR) does not provide coherentists with a principled means of answering the Problem of Justified Inconsistent Beliefs, and that nonetheless coherentists can accept (CR) and potentially answer the Problem of Justified Inconsistent Beliefs by rejecting globalist varieties of coherentism such as (C1) in favor of nonglobalist varieties such as (C2).

Acknowledgments I wish to thank Michał Araszkiewicz, Kyle Kloster, Michael Roche, Eric Senseman, and the participants in the Artificial Intelligence, Coherence and Judicial Reasoning Workshop at ICAIL 2011 (the 13th International Conference on Artificial Intelligence and Law) for helpful comments on or discussion of ancestors of this paper. Further, I wish to thank Igor Douven, Kyle Kloster, and Eric Senseman for helpful correspondence on some of the issues discussed in the paper and related issues.

\section{References}

Akiba, K. (2000), 'Shogenji’s Probabilistic Measure of Coherence Is Incoherent', Analysis 60, 356-359.

Angere, S. (2007), 'The Defeasible Nature of Coherentist Justification', Synthese 157, 321335.

Angere, S. (2008), 'Coherence as a Heuristic', Mind 117, 1-26.

BonJour, L. (1985), The Structure of Empirical Knowledge, Cambridge, Mass.: Harvard University Press.

Bovens, L. and S. Hartmann (2003a), Bayesian Epistemology, Oxford: Oxford University Press.

Bovens, L. and S. Hartmann (2003b), 'Solving the Riddle of Coherence', Mind 112, 601-633.

Bovens, L. and S. Hartmann (2005), 'Why There Cannot Be a Single Probabilistic Measure of Coherence', Erkenntnis 63, 361-374.

Bovens, L. and S. Hartmann (2006), 'An Impossibility Result for Coherence Rankings', Philosophical Studies 128, 77-91.

Bovens, L. and E. Olsson (2000), 'Coherentism, Reliability and Bayesian Networks', Mind $109,685-719$.

Bovens, L. and E. Olsson (2002), 'Believing More, Risking Less: On Coherence, Truth and Non-Trivial Extensions', Erkenntnis 57, 137-150.

Chalmers, D. (2011), 'Frege's Puzzle and the Objects of Credence', Mind 120, 587-635.

Cling, A. (2008), ‘The Epistemic Regress Problem', Philosophical Studies 140, 401-421.

Cross, C. (1999), 'Coherence and Truth Conducive Justification', Analysis 59, 186-193. 
Crupi, V., Tentori, K. and M. Gonzalez (2007), 'On Bayesian Measures of Evidential Support: Theoretical and Empirical Issues', Philosophy of Science 74, 229-252.

Day, T. and H. Kincaid. (1994), 'Putting Inference to the Best Explanation in its Place', Synthese 98, 271-295.

Dietrich, F. and L. Moretti (2005), 'On Coherent Sets and the Transmission of Confirmation', Philosophy of Science 72, 403-424.

Douven, I. (1999), 'Inference to the Best Explanation Made Coherent', Philosophy of Science 66 (Proceedings), S424-S435.

Douven, I. (2011), 'Abduction', in: E. Zalta (ed.), The Stanford Encyclopedia of Philosophy (published March 2011), http://plato.stanford.edu/entries/abduction/, accessed 1 June 2012.

Douven, I. and W. Meijs (2007), 'Measuring Coherence', Synthese 156, 405-425.

Eells, E. and B. Fitelson (2002), 'Symmetries and Asymmetries in Evidential Support', Philosophical Studies 107, 129-142.

Eliasmith, C. and P. Thagard (1997), 'Waves, Particles, and Explanatory Coherence', British Journal for the Philosophy of Science 48, 1-19.

Fitelson, B. (2003), 'A Probabilistic Theory of Coherence', Analysis 63, 194-199.

Fitelson, B. (2004), 'Two Technical Corrections to My Coherence Measure', $<$ fitelson.org/coherence2.pdf $>$.

Fitelson, B. (2008), 'A Decision Procedure for Probability Calculus with Applications', Review of Symbolic Logic 1, 111-125.

Foley, R. (1979), 'Justified Inconsistent Beliefs', American Philosophical Quarterly 16, $247-$ 257.

Garber, D. (1983), 'Old Evidence and Logical Omniscience in Bayesian Confirmation Theory', Minnesota Studies in the Philosophy of Science 10, 99-131.

Glass, D. (2005), 'Problems with Priors in Probabilistic Measures of Coherence', Erkenntnis $63,375-385$.

Harman, G. (1970), 'Induction: A Discussion of the Relevance of the Theory of Knowledge to the Theory of Induction (With a Digression to the Effect that neither Deductive Logic nor the Probability Calculus has Anything to do with Inference)', in: M. Swain (ed.), Induction, Acceptance, and Rational Belief, Dordrecht: Reidel, 83-99.

Huemer, M. (1997), 'Probability and Coherence Justification', Southern Journal of Philosophy 35, 463-472.

Huemer, M. (2007), 'Weak Bayesian Coherentism', Synthese 157, 337-346.

Huemer, M. (2009a), 'Explanationist Aid for the Theory of Inductive Logic', British Journal for the Philosophy of Science 60, 345-375.

Huemer, M. (2009b), 'When is Parsimony a Virtue?', Philosophical Quarterly 59, 216-236.

Huemer, M. (2011), 'Does Probability Theory Refute Coherentism?', Journal of Philosophy $108,35-54$.

Iranzo, V. (2008), 'Bayesianism and Inference to the Best Explanation', Theoria 61, 89-106.

Kemeny, J., and P. Oppenheim (1952), 'Degree of Factual Support', Philosophy of Science 19, 307-324.

Klein, P. and T. Warfield (1994), 'What Price Coherence?', Analysis 43, 129-132. 
Klein, P. and T. Warfield (1996), 'No Help for the Coherentist', Analysis 56, 118-121.

Kvanvig, J. (2012), 'Coherentism and Justified Inconsistent Beliefs: A Solution', Southern Journal of Philosophy 50, 21-41.

Lehrer, K. (1999), 'Justification, Coherence and Knowledge', Erkenntnis 50, 243-258.

Lewis, C. I. (1946), An Analysis of Knowledge \& Valuation, La Salle: Open Court.

Lipton, P. (2001), 'Is Explanation a Guide to Inference? A Reply to Wesley C. Salmon', in: G. Hon and S. Rakover (eds.), Explanation: Theoretical Approaches and Applications, Dordrecht: Kluwer, 93-120.

Lipton, P. (2004), Inference to the Best Explanation (2nd ed.), London: Routledge.

Lombrozo, T. (2007), 'Simplicity and Probability in Causal Explanation', Cognitive Psychology 55, 232-257.

Lycan, W. (1996), 'Plantinga and Coherentisms', in: J. Kvanvig (ed.), Warrant in Contemporary Epistemology: Essays in Honor of Plantinga's Theory of Knowledge, Lanham: Rowman \& Littlefield, 3-23.

Lycan, W. (2012), 'Explanationist Rebuttals (Coherentism Defended Again)', Southern Journal of Philosophy 50, 5-20.

McGrew, T. (2003), 'Confirmation, Heuristics, and Explanatory Reasoning', British Journal for the Philosophy of Science 54, 553-567.

Meijs, W. (2006), 'Coherence as Generalized Logical Equivalence', Erkenntnis 64, 231-252.

Meijs, W. and I. Douven (2007), 'On the Alleged Impossibility of Coherence', Synthese 157, 347-360.

Merricks, T. (1995), 'On Behalf of the Coherentist', Analysis 55, 306-309.

Niiniluoto, I. (1999), 'Defending Abduction', Philosophy of Science 66 (Proceedings), S436S451.

Niiniluoto, I. (2004), 'Truth-Seeking by Abduction', in: F. Stadler (ed.), Induction and Deduction in the Sciences, Dordrecht: Kluwer, 57-82.

Okasha, S. (2000), 'Van Fraassen's Critique of Inference to the Best Explanation', Studies in History and Philosophy of Science 31, 691-710.

Olsson, E. (1997), 'Coherence and the Modularity of Mind', Australasian Journal of Philosophy 75, 404-411.

Olsson, E. (1999), 'Cohering With', Erkenntnis 50, 273-291.

Olsson, E. (2001), 'Why Coherence Is Not Truth-Conducive', Analysis 61, 236-241.

Olsson, E. (2002), 'What Is the Problem of Coherence and Truth?', Journal of Philosophy 99, 246-272.

Olsson, E. (2005a), Against Coherence: Truth, Probability and Justification, Oxford: Oxford University Press.

Olsson, E. (2005b), 'The Impossibility of Coherence', Erkenntnis 63, 387-412.

Olsson, E. and T. Shogenji (2004), 'Can We Trust Our Memories? C. I. Lewis's Coherence Argument', Synthese 142, 21-41.

Poston, T. (2012), 'Basic Reasons and First Philosophy: A Coherentist View of Reasons', Southern Journal of Philosophy 50, 75-93.

Psillos, S. (2004), 'Inference to the Best Explanation and Bayesianism', in: F. Stadler (ed.), Induction and Deduction in the Sciences, Dordrecht: Kluwer, 83-91. 
Psillos, S. (2007), 'The Fine Structure of Inference to the Best Explanation', Philosophy and Phenomenological Research 74, 441-448.

Roche. W. (2010), 'Coherentism, Truth, and Witness Agreement', Acta Analytica 25, 243257.

Roche, W. (2011), 'Coherentism and Inconsistency', Southwest Philosophy Review 27, 185 193.

Roche, W. (2012a), 'Witness Agreement and the Truth-Conduciveness of Coherentist Justification', Southern Journal of Philosophy 50, 151-169.

Roche, W. (2012b), 'A Reply to Cling's 'The Epistemic Regress Problem', Philosophical Studies 159, 263-276.

Salmon, W. (1970), 'Bayes's Theorem and the History of Science', Minnesota Studies in the Philosophy of Science 5, 68-86.

Salmon, W. (1990), 'Rationality and Objectivity in Science or Tom Kuhn Meets Tom Bayes', Minnesota Studies in the Philosophy of Science 14, 175-204.

Salmon, W. (2001a), 'Explanation and Confirmation: A Bayesian Critique of Inference to the Best Explanation', in: G. Hon and S. Rakover (eds.), Explanation: Theoretical Approaches and Applications, Dordrecht: Kluwer, 121-136.

Salmon, W. (2001b), 'Reflections of a Bashful Bayesian: A Reply to Lipton', in: G. Hon and S. Rakover (eds.), Explanation: Theoretical Approaches and Applications, Dordrecht: Kluwer, 61-91.

Schubert, S. (2012), 'Coherence Reasoning and Reliability: A Defense of the Shogenji Measure', Synthese 187, 305-319.

Schubert, S. and E. Olsson. (2012), 'On the Coherence of Higher-Order Beliefs', Southern Journal of Philosophy 50, 112-135.

Schupbach, J. (2008), 'On the Alleged Impossibility of Bayesian Coherentism', Philosophical Studies 141, 323-331.

Schupbach, J. (2011), 'New Hope for Shogenji's Coherence Measure', British Journal for the Philosophy of Science 62, 125-142.

Senseman, E. (2010), 'The Problem of Justified Inconsistent Beliefs: A Case for Coherentism', unpublished manuscript.

Shogenji, T. (1999), 'Is Coherence Truth Conducive?', Analysis 59, 338-345.

Shogenji, T. (2001), 'Reply to Akiba on the Probabilistic Measure of Coherence', Analysis 61, 147-150.

Shogenji, T. (2005), 'Justification by Coherence from Scratch', Philosophical Studies 125, 305-325.

Shogenji, T. (2007), 'Why Does Coherence Appear Truth-Conducive?', Synthese 157, 361372.

Shogenji, T. (forthcoming), 'Coherence of the Contents and the Transmission of Probabilistic Support', Synthese.

Siebel, M. (2004), 'On Fitelson's Measure of Coherence', Analysis 64, 189-190.

Siebel, M. (2005), 'Against Probabilistic Measures of Coherence', Erkenntnis 63, 335-360.

Siebel, M. (2011), 'Why Explanation and Thus Coherence Cannot be Reduced to Probability', Analysis 71, 264-266. 
Siebel, M. and W. Wolff (2008), 'Equivalent Testimonies as a Touchstone of Coherence Measures', Synthese 161, 167-182.

Sober, E. (2002), 'Bayesianism-Its Scope and Limits', in: R. Swinburne (ed.), Bayes's Theorem, Cambridge: Cambridge University Press, 21-38.

Swinburne, R. (1973), An Introduction to Confirmation Theory, London: Methuen.

Thagard, P. (1989a), 'Explanatory Coherence', Behavioral and Brain Sciences 12, 435-467.

Thagard, P. (1989b), 'Author's Response', Behavioral and Brain Sciences 12, 490-499.

Thagard, P. (1992), Conceptual Revolutions, Princeton: Princeton University Press.

Thagard, P. (2000), Coherence in Thought and Action, Cambridge, Mass.: MIT Press.

Thagard, P. (2004), 'Causal Inference in Legal Decision Making: Explanatory Coherence vs. Bayesian Networks’, Applied Artificial Intelligence 18, 231-249.

Thagard, P. (2012), 'Coherence: The Price is Right', Southern Journal of Philosophy 50, $42-$ 49.

Thagard, P. and G. Nowak (1988), 'The Explanatory Coherence of Continental Drift', PSA: Proceedings of the Biennial Meeting of the Philosophy of Science Association 1988, 118126.

Thagard, P. and K. Verbeurgt (1998), 'Coherence as Constraint Satisfaction', Cognitive Science 22, 1-24.

Tregear, M. (2004), 'Utilising Explanatory Factors in Induction?', British Journal for the Philosophy of Science 55, 505-519.

van Cleve, J. (2005), 'Why Coherence Is Not Enough: A Defense of Moderate Foundationalism', in: M. Steup and E. Sosa (eds.), Contemporary Debates in Epistemology, Malden: Blackwell, 168-180.

van Cleve, J. (2011), 'Can Coherence Generate Warrant Ex Nihilo? Probability and the Logic of Concurring Witnesses', Philosophy and Phenomenological Research 82, 337-380.

van Fraassen, B. (1989), Laws and Symmetry, Oxford: Oxford University Press.

Weisberg, J. (2009), 'Locating IBE in the Bayesian Framework', Synthese 167, 125-143.

Wheeler, G. (2009), 'Focused Correlation and Confirmation', British Journal for the Philosophy of Science 60, 79-100.

Wheeler, G. (2012), 'Explaining the Limits of Olsson's Impossibility Result', Southern Journal of Philosophy 50, 136-150. 